\title{
La concepción de la docencia sobre la cultura ibérica de Pere Bosch Gimpera en 1917 a partir de los apuntes de clase de Lluís Pericot
}

\author{
Pere Bosch Gimpera's concept of teaching Iberian culture in 1917 from the class notes \\ of Lluís Pericot
}

Francisco Gracia Alonso ${ }^{a}$

\section{RESUMEN}

Desde la creación de la Escuela Superior de Diplomática en 1856, la docencia de la Prehistoria y la Arqueología estuvo supeditada a la construcción de un relato unificado de la Historia de España y a las necesidades del Cuerpo Facultativo de Archiveros, Bibliotecarios y Arqueólogos. En 1917, un año después de conseguir la cátedra de Historia Universal Antigua y Media en la Universidad de Barcelona, Pere Bosch Gimpera impartió su primer curso monográfico sobre la Cultura Ibérica. El contenido de la asignatura antepondrá los resultados de la investigación arqueológica al conocimiento de las fuentes clásicas para el análisis de las estructuras territoriales, sociales, ideológicas y políticas de la Protohistoria de la península ibérica. Este cambio esencial caracterizará el pensamiento de los integrantes de la Escuela de Arqueología de Barcelona durante las décadas siguientes. Sin embargo la visión arcaica de la concepción de la Prehistoria y la Protohistoria como unos apartados menores en el estudio de la Historia seguirá en las universidades españolas, donde la investigación arqueológica tampoco fue axial. Este trabajo analiza los planteamientos de Bosch a partir de los apuntes tomados en sus clases por su principal discípulo, Lluís Pericot. versal History at the University of Barcelona, Pere Bosch Gimpera taught his first monographic course on Iberian Culture. In it he would put the results of the archaeological investigation before the knowledge of the classical sources for the analysis of the territorial, social, ideological and political structures of the Protohistory of the Iberian peninsula. This essential change would characterize the thinking of the members of the Barcelona School of Archeology during the following decades. However, the archaic view that Prehistory and Protohistory were minor sections in the study of History will continue in Spanish universities, where archaeological research was not axial. This work analyzes Bosch's approaches based on the notes taken in his classes by his main disciple, Lluís Pericot.

Palabras clave: Historiografía; Arqueología; Siglos XIXXX; Universidad de Barcelona; Pere Bosch Gimpera; Asignatura de Cultura Ibérica; Metodología docente; Lluís Pericot.

Key words: Historiography; Archeology; XIX-XX centuries; University of Barcelona; Pere Bosch Gimpera; Iberian Culture Lessons; Teaching methodology; Lluis Pericot.

\section{LA CONCEPCIÓN DE LA INVESTIGACIÓN Y DOCENCIA SOBRE LA CULTURA IBÉRICA EN LAS UNIVERSIDADES ESPAÑOLAS CON ANTERIORIDAD A 1916}

Tras la creación de la Escuela Superior de Diplomática (ESD) el 7 de octubre de $1856^{1}$ y la promul-

\footnotetext{
${ }^{1}$ Archivo General de la Administración, Alcalá de Henares, Madrid (AGA). Educación y Ciencia (05) 016.000. Legajo 32/16304. Escuela de Diplomática. Su creación y organización. Oficio de la Dirección de Instrucción Pública al presidente de la RAH de 29 de agosto de 1856. Gaceta de Madrid, núm. 1.375, 9 de octubre de 1856, p. 1. Decreto
} 
gación de la Ley de Instrucción Pública de $1857^{2}$, la docencia de la arqueología en España quedó supeditada a los intereses de la ESD y de la Real Academia de la Historia como parte de un modelo de construcción del relato de la Historia de España. Su objetivo era definir una argumentación ideológica utilizable como elemento de cohesión social por los gobiernos de la alternancia durante el primer cuarto de siglo de la Restauración (Peiró 1996a; Almagro Gorbea 2007; Maier 2008; Mederos 2013). La necesidad de potenciar los conceptos de unidad administrativa, territorial y lingüística, junto al papel predominante de la religión cristiana y de la monarquía en la evolución del estadonación, confirieron especial importancia a la historia y la arqueología medievales. El interés por articular el período de la reconquista como crisol formativo de una determinada idea de España coincidía con el modelo francés basado en la École des Chartes (Guyotjeannin 1993; AA. VV 2015). El resultado será la escasa presencia de los temas de Prehistoria y Protohistoria en los temarios docentes, y en la documentación aportada por opositores y tribunales en los concursos de oposición a cátedras universitarias de Historia y Arqueología antes de 1916 (Ayarzagüena 1993; Berlanga 2001; García Santos 2017). El reglamento de oposiciones vigente desde $1910^{3}$, establecido por el ministro de Instrucción Pública y Bellas Artes Álvaro de Figueroa y Torres, conde de Romanones, reafirmaba los procedimientos de la Ley de 1857 . Según ellos, en el transcurso del acto de presentación ante el tribunal, los opositores debían entregar un programa detallado de la materia objeto del concurso. A partir de los temarios aportados, los miembros del tribunal elaboraban uno propio que era entregado a los firmantes de la plaza. Un sorteo establecía los temas de unos y otros que deberían ser expuestos en las pruebas por los opositores.

El análisis de los temarios de las plazas convocadas entre 1875 y 1916 muestra la disparidad en la formación de los opositores y su falta de especialización en una temática o cronología específica. Ello era producto de una docencia generalista $\mathrm{y}$, en muchos casos, prueba que los candidatos, en especial los que se habían beneficiado de pensiones de la Junta para Ampliación de Estudios e Investigaciones Científicas en el extranjero, tenían un conocimiento más profundo y moderno de la materia que los integrantes de los tribunales. Pugnarán quienes aportaban temarios renovadores con aquellos que se ajustaban al concepto de docencia que representaban los jueces para defender

orgánico y Reglamento de la Escuela de Diplomática, dados por S. M. a 7 de octubre de 1856 y 11 de febrero de 1857 .

${ }^{2}$ Gaceta de Madrid, núm. 1710, 10 de septiembre de 1857, pp. 1-3.

${ }^{3}$ Gaceta de Madrid, núm. 104, 14 de abril de 1910,pp. 101-102. la denominada "visión redonda de la asignatura". La documentación sobre la docencia de la Prehistoria de las oposiciones a cátedras de Historia Universal antigua y media, Historia de España antigua y media, y Arqueología, Epigrafía y Numismática, muestra también las visiones enfrentadas entre el providencialismo y el evolucionismo, además del debate sobre su reconocimiento como ciencia que marcó el desarrollo de la investigación en España durante la segunda mitad del siglo XIX (Gracia en prensa) ${ }^{4}$.

Un ejemplo es el temario del tribunal designado para cubrir la vacante de Historia Universal de las Edades Antigua y Media en la Universidad de Valencia en 1906 -que obtendría José Deleito y Piñuela-, presidido por Manuel del Valle Cárdenas. En sus 134 temas la Historia era concebida como una estructura troncal a la que la Geografía, la Cronología, la Antropología y la Filología ayudaban en la generación del conocimiento. En cambio la Arqueología no se nombraba, consecuencia de su vinculación con la Historia del Arte para la época clásica y con la Geología y la Paleontología para las estructuras sociales consideradas como no históricas ${ }^{5}$. Cuatro temas cubrían el período comprendido entre el Paleolítico -nomenclatura que no se emplea- y la Edad de los Metales. Los epígrafes mostraban el atraso en la incorporación del conocimiento científico al mantener ideas superadas como la raciología o la periodización antidarwinista de Jean Louis Armand de Quatrefages (1810-1892) expresada en sus obras Charles Darwin et ses précurseurs français: étude sur le transformisme (1870), L'espèce humaine (1877) y Histoire générale des races humaines (1887-1889). Además el tribunal hacía frecuentes alusiones a los textos bíblicos o a la religión como modelos interpretativos. La protohistoria peninsular no se citaba y, en general, las referencias específicas correspondían a la Edad Media, muy sobredimensionada.

La estructura es muy similar a la planteada por el tribunal que había juzgado, en 1903, bajo la presidencia de Matías Barrio y Mier, las vacantes de Historia Universal en las universidades de Barcelona, Granada y Sevilla que obtendrían respectivamente Martiniano Martínez Ramírez, José Salarrullana de Dios y Feliciano Candau Pizarro. La comisión definió 153 temas. Sólo cinco de ellos, dedicados a la concepción racial de la evolución humana, correspondían a la Prehistoria, un concepto que no se emplea pese a haberse publi-

\footnotetext{
${ }^{4}$ Sobre el desarrollo de la concepción de la Historia en España durante la segunda mitad del siglo XIX y principios del XX, véase Peiró y Pasamar 1989-1990; Peiró 1996b.

5 AGA. 5384 (1). 32/7392. Cuestionario de las oposiciones a la cátedra de Historia Universal antigua y media de la Universidad de Valencia.
} 


\begin{tabular}{|c|c|}
\hline \multicolumn{2}{|c|}{ Tribunal. Temas de "protohistoria" y colonización fenicia y griega 1911} \\
\hline \multicolumn{2}{|c|}{ "Concepto, origen y progresos de la protohistoria. Estado actual de los estudios relativos a la protohistoria ibérica" } \\
\hline \multicolumn{2}{|c|}{$\begin{array}{l}\text { "Protohistoria ibérica. Los períodos arqueolítico y neolítico. Conclusiones más probables acerca de la procedencia y } \\
\text { caracteres de las primitivas razas que poblaron a España" }\end{array}$} \\
\hline \multicolumn{2}{|l|}{ "Protohistoria ibérica. Edad de los metales" } \\
\hline \multicolumn{2}{|c|}{ "Primeras fuentes literarias para el conocimiento de la Historia de España" } \\
\hline \multicolumn{2}{|c|}{ "Juicio de las tradiciones y leyendas relativas a los primitivos tiempos de nuestra historia" } \\
\hline Tribunal & Claudio Sanz Arizmendi, ganador de la plaza \\
\hline $\begin{array}{l}\text { "Los iberos. Su procedencia y su establecimiento } \\
\text { en España. Tribus en que se hallaban divididos. } \\
\text { Su estado social y religioso" }\end{array}$ & $\begin{array}{l}\text { "Los Iberos. La raza ibera: textos acerca de su existencia. Caracteres } \\
\text { étnicos de los iberos. Su procedencia probable: el mito de Hércules, } \\
\text { opiniones de Humboldt y Brugsch. Tribus ibéricas según Herodoto y } \\
\text { según los autores latinos. Costumbres y cultura de los iberos" }\end{array}$ \\
\hline $\begin{array}{l}\text { "Los celtas. Su origen, su llegada a España, sus } \\
\text { tradiciones. Estado social de los celtas" }\end{array}$ & $\begin{array}{l}\text { "Los celtas. Opiniones acerca de su origen: caracteres comunes a } \\
\text { celtas y escitas. La Gallia céltica. Entrada de los celtas en España: } \\
\text { territorios que ocuparon sus tribus. Creencias religiosas de los celtas, } \\
\text { su culto. Costumbres de este pueblo" }\end{array}$ \\
\hline $\begin{array}{l}\text { "Los celtíberos: su territorio, sus tribus, su } \\
\text { organización social" }\end{array}$ & $\begin{array}{l}\text { "Los celtíberos. Origen de este pueblo: fusión de iberos y celtas. } \\
\text { Límites y divisiones de la Celtiberia. Principales tribus celtiberas. } \\
\text { Organización social y política de este pueblo según las inscripciones } \\
\text { encontradas: el individuo, la familia, la gens, la tribu y la } \\
\text { confederación de tribus. Causas que detuvieron su desarrollo. } \\
\text { Significación de este pueblo en la historia patria" }\end{array}$ \\
\hline
\end{tabular}

Tab. 1. Cuestionario de oposiciones a la cátedra de Historia de España, en la Antigüedad y la Edad Media vacante en la Universidad de Sevilla. AGA. 5386 (3). 32/7398. Leg. 5386-6 1911 y Programa de Historia de España. Edades Antigua y Media. Claudio Sanz Arizmendi, 31 de diciembre de 1910. AGA. 5386 (3). 32/7398. Leg. 5386-6.

cado ya obras como Archaeology and Prehistoric Annals of Scotland (1851) y Prehistoric Man (1862) de Daniel Wilson (1816-1892). Barrio y Mier presidirá también en 1903 las oposiciones para la provisión de la cátedra de Historia Universal Edad Antigua y Media en la Universidad de Zaragoza ${ }^{6}$. Los planteamientos eran similares, por cuanto la investigación y enseñanza de la Historia definida por el tribunal se basaba exclusivamente en el estudio de los documentos escritos desde una perspectiva positivista. Se propusieron 119 temas. Entre los ocho dedicados a la Prehistoria, el epígrafe "Cómo se debe proceder al efectuar una excavación” incluirá la primera referencia a la importancia de la arqueología. Se incluyó la denominación de algunas fases del Paleolítico medio y superior, pero se mantuvo la problemática del hombre terciario; la neolitización se redujo al megalitismo, y la Edad de los Metales a la explicación difusionista de la metalurgia del bronce.

En 1911, Juan Catalina García-López presidió, hasta su fallecimiento el 18 de enero, el tribunal para la provisión de la vacante de la cátedra de Historia de

${ }^{6}$ AGA. 5383 (2). 32/7391. 5383-5. Expediente de las oposiciones a la cátedra de Historia Universal, edad antigua y media de la Facultad de Filosofia y Letras de la Universidad de Zaragoza.
España Antigua y Media en la Universidad de Sevilla ${ }^{7}$ con un amplísimo temario de 165 epígrafes $^{9}$. Los arqueólogos Catalina García-López y el marqués de Cerralbo formaban parte del tribunal pero, aun así, en vez del concepto prehistoria, se empleó el de protohistoria para las cronologías más antiguas, entendidos todavía entonces por muchos historiadores como sinónimos. Los ocho temas que se le dedicaron cubrían desde el "arqueolítico" inicial hasta la conquista romana (Tab. 1). La aportación más interesante fue que entre los dedicados a las colonizaciones fenicia y griega, había temas específicos sobre iberos, celtas y celtíberos, aunque tratados siempre a partir de informaciones aportadas por los textos clásicos y no por la investigación arqueológica. Claudio Sanz Arizmendi, que obtendría la plaza, tras reafirmar las ideas de "Historia nacional" e "Historia patria" propias del discurso narrativo-político contemporáneo, diferenció en su programa los "Tiempos primitivos". Su rechazo como parte de la Historia de cualquier período que no pudiera ser analizado a partir de textos escritos se reafirma en el enunciado de los primeros epígrafes como

\footnotetext{
7 Integraban la comisión Pío Zabala Lera, Andrés Giménez Soler, Román Gómez Villafranca y Enrique de Aguilera y Gamboa, marqués de Cerralbo.
} 
el de "Restos e indicios del tránsito a la Historia" dedicado a la Edad de los Metales. Sanz Arizmendi empezaba la Historia peninsular con las leyendas sobre Tubal, Tharsis y la Atlántida, explicando las colonizaciones fenicia y griega en función de los textos literarios. Sin embargo para corroborarlos incluye los primeros resultados de las intervenciones en Ampurias iniciadas dos años antes. Dedica tres de las ochenta y nueve lecciones a iberos, celtas y celtíberos (Tab. 1) pero, de nuevo, las descripciones son de base estrictamente literaria. Obvia ejemplos importantes como las intervenciones de Schulten y de la Comisión Española en Numancia, iniciadas en 1905, refiriéndose, en cambio, a las obras de Alexander von Humboldt Prüfung der Untersuchungen über die Urbewohner Hispaniens vermittelstder Vaskiscben Sprache (1821) y Heinrich Karl Brugsch Historique d'Égypte, 1, Introduction, Histoire des dynasties I-XVII (1875).

La línea ideológica marcada en estos ejemplos se consolidará en la mayoría de los cuestionarios de las oposiciones a cátedras, tanto de Historia de España como de Historia Universal, incluyendo las especificadas como "antigua y medieval". También hubo algun cambio como en las oposiciones para cubrir, en 1909, la vacante de Historia Universal en la Universidad de Valencia ${ }^{8}$. El tribunal encargó a Germán Latorre Setién, catedrático de Geografía política y descriptiva en la Universidad de Sevilla, elaborar la parte del temario correspondiente a la Prehistoria. El vencedor, Francisco de Paula Amat y Villalba, en su propuesta, otorgó a la Prehistoria una importancia residual además de definirla con términos periclitados ${ }^{9}$. Por el contrario, el planteamiento de Latorre superaba los conceptos conservadores indicados con una visión más avanzada que primaba la "reconstrucción de las sociedades". Reconocía el carácter científico de la Prehistoria; establecía las relaciones con la Historia; definía sus límites cronológicos, y enunciaba la existencia de una metodología específica de trabajo. Recurría a una división clásica en tres etapas: Arqueolítico, Neolítico y Edad de los Metales, pero se distanciaba de la enunciación tipológica propia de la influencia de la escuela histórico-cultural francesa para proponer una interpretación histórica de los procesos. Para ello, en los tres temas, dedicaba un apartado al "estado social del hombre", sin duda lo más próximo a una interpretación transversal, plural, ideológica y social, propuesta hasta el momento.

El posicionamiento de Latorre era el resultado de la influencia de Manuel Sales y Ferré, catedrático de

\footnotetext{
8 AGA. 5386 (1). 32/7396. Tribunal de oposiciones a la cátedra de Historia Universal de la Universidad de Valencia. Cuestionario 1909.

9 AGA. 5386 (1). 32/7396. Programa de Historia Universal por Francisco de Paula Amat y Villalba.
}

Historia Universal en la misma Universidad de Sevilla, quien, conocedor de la bibliografía francesa, había introducido sus postulados en sus obras El hombre primitivo y las tradiciones orientales. La ciencia y la religión (1881) y Compendio de Historia Universal. Edad prehistórica y periodo oriental (1883-1886).

Con anterioridad a 1916 se cubrieron las vacantes de Arqueología en las universidades de Valencia, Central y Barcelona. La de Arqueología, Numismática y Epigrafía de la Universidad de Valencia fue la primera con dicha denominación cubierta por concurso en el sistema universitario español ${ }^{10}$. Fue resultado de la amplia remodelación de los estudios de la Facultad de Filosofía y Letras de dicha universidad iniciada por resolución de 18 de septiembre de 1903. La plaza fue declarada, en primera instancia, vacante el 30 de abril de 1904 y convocada de nuevo el 28 de julio. Un tribunal presidido por Catalina García-Lopez ${ }^{11}$ juzgó las pruebas en la sede del Museo Arqueológico Nacional, proponiendo el 22 de mayo de 1905 a Luis Gonzalvo París tras una dura pugna interna ${ }^{12}$. El cuestionario elaborado por la comisión es un reflejo de la arqueología española de la segunda mitad del siglo $\mathrm{XIX}^{13}$. En sus 115 temas ni había cuestiones metodológicas ni se reconocía la Arqueología como ciencia. En cambio, en un buen ejemplo de la importancia dada a la erudición de los escritores e ilustrados desde el siglo XVI, se dedicaron seis temas al estudio de sus obras (Tab. 2). La serie de José María Quadrado Nieto, Recuerdos y Bellezas de España, editada entre 1839 y 1886, era la entrada más reciente. Quedaba así de manifiesto el desconocimiento de la arqueología clásica moderna vigente en Europa, en especial los trabajos de la Escuela Alemana, representada, entre otros por Loeschke, Furtwängler, Frickenhaus, Karo, Schliemann, Dragendorff y Jacobsthal ${ }^{14}$. Los seis apartados del temario dedicados a la arqueología prehistórica cubren desde el Paleolítico (todavía "Arqueolítico"), hasta la arquitectura de la Edad de los Metales, con especial atención al arte rupestre y a la arquitectura y a la cultura material a partir del Neolítico. El bloque principal de epígrafes correspondía a la Arqueología Medieval, definiendo así tanto la continuidad de los postulados de la ESD como el inicio de tres décadas de preeminencia de esa línea teórica en los concursos para las vacantes en Arqueología.

\footnotetext{
${ }^{10}$ Gaceta de Madrid, núm. 265, 22 de septiembre de 1903, p. 2503.

${ }^{11}$ Gaceta de Madrid, núm. 38, 7 de febrero de 1905, p. 486. 1905.

${ }_{12}$ AGA. 5385 (2). 32/7395. Acta de la sesión de 16 de mayo de

${ }_{13}$ AGA. 5385(2). 32/7395. Oposiciones a la Cátedra Arqueología, Numismática y Epigrafia de la Universidad de Valencia. Cuestionario.

${ }^{14}$ Sobre el desarrollo de la Arqueología clásica en Europa durante la segunda mitad del siglo XIX y principio del XX, véase Gran Aymerich (2007).
} 


\begin{tabular}{|c|}
\hline mbrosio de Morales. Discurso sobre las antigüedades de Castilla y Antigüedades de las ciudades de España, 1575. \\
\hline Antonio Agustín Albanell. Diálogos de medallas, inscripciones y otras antigüedades, 1587. \\
\hline Rodrigo Caro. Relación de las inscripciones y antigüedad de la Villa de Utrera, 1620. \\
\hline $\begin{array}{l}\text { Rodrigo Caro. Antigüedades y principado de la Ilustrísima ciudad de Sevilla y corografía de su convento juridico o } \\
\text { antigua Chancillería, 1634. }\end{array}$ \\
\hline José Ortiz y Sanz. Viaje arquitectónico-anticuario de España, 1807 (Canto 2001). \\
\hline $\begin{array}{l}\text { Isidoro Bosarte. Disertación sobre los monumentos, la pintura, escultura y arquitectura que se hallan en la ciudad de } \\
\text { Barcelona, } 1786 .\end{array}$ \\
\hline $\begin{array}{l}\text { Isidoro Bosarte. Observaciones sobre las Bellas Artes entre los antiguos hasta la conquista de Grecia por los Romanos } \\
\text { 1790-1791. }\end{array}$ \\
\hline $\begin{array}{l}\text { Isidoro Bosarte. Viaje artístico a varios pueblos de España, con el juicio de las tres Nobles Artes que en ellos existen, y } \\
\text { épocas a que pertenecen, } 1804 \text {. }\end{array}$ \\
\hline $\begin{array}{l}\text { Juan Agustín Ceán Bermúdez. Sumario de las antigüedades romanas que hay en España, en especial las pertenecientes a } \\
\text { las Bellas Artes, } 1832 \text {. }\end{array}$ \\
\hline
\end{tabular}

Tab. 2. Relación, por orden cronológico, de obras de eruditos de los siglos XVI a XIX que eran temas de estudio en el cuestionario de 1904 para las Oposiciones a la Cátedra Arqueologí, Numismática y Epigrafía de la Universidad de Valencia.

Es evidente que la investigación no constituía una prioridad años antes de la promulgación de la Ley de Excavaciones de $1911^{15}$ y su Reglamento de $1912^{16}$. Se precisaban funcionarios del Cuerpo Facultativo de Archiveros, Bibliotecarios y Arqueólogos (CFABA), responsables de la protección, conservación y catalogación del patrimonio histórico-arqueológico centrado en las artes industriales y religiosas medievales, de largo el núcleo de las colecciones de los museos. Por ello es lógico que hubiese tres temas vinculados con la museología: "Principios sobre la organización de un Museo Arqueológico general. Catalogación", "Idea de la clasificación y de las colecciones del Museo Arqueológico Nacional" y "Idea de los museos arqueológicos principales de Europa" ${ }^{17}$. Una década después ya no aparecerán en el temario elaborado para la oposición a la plaza de Barcelona, aunque la estructura de repartición temática, como se verá, fuera muy similar. La razón obvia es que, en 1914, ya existía una legislación específica en el ámbito de la arqueología y la Junta Superior de Excavaciones y Antigüedades y la Comisión de Investigaciones Paleontológicas y Prehistóricas, en Madrid, y la Sección Histórico-Arqueológica del Institut d'Estudis Catalans, en Barcelona, desarrollaban o financiaban con fondos públicos campañas de intervención programadas. Por el mismo motivo, no hay temas dedicados a la arqueología de la península ibérica que sí caracterizarán, en mayor o

\footnotetext{
15 Gaceta de Madrid, núm. 189, 8 de julio de 1911, pp. 95-96.

16 Gaceta de Madrid, núm. 65, 5 de marzo de 1912, pp. 671-673.

17 AGA. 5385(2). 32/7395. Oposiciones a la Cátedra Arqueología Numismática y Epigrafía de la Universidad de Valencia. Cuestionario. Temas 73,74 y 75 .
}

menor media, las oposiciones posteriores, como resultado de la importancia que irán adquiriendo las intervenciones monumentales en Numancia, Mérida o Ampurias. Las diferencias de criterio se aprecian también en la bibliografía empleada por los opositores para preparar los temas. Solo Gonzalvo París cita publicaciones extranjeras y declara conocer los trabajos de Heinrich Schliemann sobre Troya y Tirinto ${ }^{18}$, además de los de Émile Cartailhac y Henri Breuil entre 1902 y 1905 sobre las pinturas rupestres de Altamira y los referidos a la península ibérica de Louis Siret y Cels, Les premiers ages du métal dans le sud-est de l'Espagne (1888) y L'Espagne préhistorique (1893) y Pierre Paris, Essai sur l'art et l'industrie de l'Espagne primitive (1903-1904).

En la Universidad Central, Catalina García-López y José Ramón Mélida y Alinari marcaron las décadas 1900-1930. El primero ocupó la cátedra entre 1900 y 1911 tras la remodelación de los estudios universitarios y la supresión de la ESD ${ }^{19}$. La asignatura de Arqueología (una clase cada dos días) se daba en el plan de estudios de Historia en la Facultad de Filosofía y Le$\operatorname{tras}^{20}$. Tras su fallecimiento, Mélida cubrió la cátedra por designación directa del Ministerio de Instrucción Pública y Bellas Artes y nombramiento de $1911^{21}$, se-

\footnotetext{
${ }_{18}$ H. Schliemann. Ithaque, le Péloponnèse, Troie. Recherches archéologiques, 1869; Troja. Results of the latest researches on the site of Homer's Troy, 1884; Tiryns. Der prähistorische Palast der Könige von Tiryns. Ergebnisse der neuesten Ausgrabungen, 1885; Ilios, ville et pays des Troyens. Fouilles de 1871 à 1882, 1885).

19 Gaceta de Madrid, núm, 219, 7 de agosto de 1900, pp. 530-531; núm. 203, 22 de julio de 1900, pp. 310-311.

${ }^{20}$ Gaceta de Madrid, núm. 263, 20 de septiembre de 1900, p. 1143.

${ }^{21}$ Gaceta de Madrid, núm. 13, 13 de enero de 1912, p. 110.
} 
gún lo previsto en la Ley de Educación de 1857 y medidas posteriores ${ }^{22}$ que facilitaban el nombramiento discrecional de personas de reconocido prestigio (DíazAndreu 2004: XCI-XCIV). Los informes de la Facultad de Filosofía y Letras, del Consejo de Instrucción Pública y de la Real Academia de la Historia destacaron la labor de Mélida como conservador del Museo Arqueológico Nacional y miembro del CFABA y, en especial, su implicación en las excavaciones de $\mathrm{Nu}$ mancia, la gran obra de arqueología patriótica iniciada pocos años antes.

La primera cátedra cubierta por concurso libre en la Universidad Central fue la de Arqueología arábiga correspondiente a los estudios de doctorado de la Facultad de Filosofía y Letras ${ }^{23}$. El tribunal, nombrado el 5 de diciembre de 1911 y presidido inicialmente por Eduardo Saavedra Moragas, sufriría dos cambios. Primero se nombró al hebraísta Mariano Viscasillas y Urriza ${ }^{24}$, substituido tras su fallecimiento, por José Joaquín Herrero y Sánchez ${ }^{25}$. Realizadas las pruebas, Manuel Gómez-Moreno Martínez sería nombrado catedrático el 19 de julio de $1913^{26}$. Ese año la asignatura de Arqueología arábiga pasaría a ser obligatoria para la obtención del doctorado en Historia en la reforma de los planes de estudio de la Facultad de Filosofía y Letras, asegurando alumnos a Gómez-Moreno ${ }^{27}$.

José Vicente Amorós Barra obtuvo el nombramiento de catedrático de Arqueología, Epigrafía y Numismática en la Universidad de Barcelona en $1914^{28}$ tras un dilatado proceso, puesto que la plaza fue convocada el 31 de agosto de $1911^{29}$, a la vez que se nombró el tribunal presidido por Eduardo Hinojosa y Naveros. Le sustituiría José Joaquín Herrero, quien aprovechaba su posición en el Consejo de Instrucción Pública para controlar las oposiciones. Los miembros de la comisión elaboraron un temario integrado por 130 epígrafes $^{30}$. Su estructura muestra la continuidad con la línea docente marcada por la ESD priorizando la Arqueolo-

${ }^{22}$ Ley de Educación 1857, art. 238 y 239; disposición de 24 de abril de 1908 en Gaceta de Madrid, núm. 299, 26 de octubre de 1910, p. 248. y R. D. de 21 de octubre de 1910.

${ }^{23}$ AGA. Educación. Legajo 32/7404. Archivo Histórico Nacional, Madrid (AHN). Sección de Universidades. Universidad Central, 6567. Expediente 14.

${ }^{24}$ Gaceta de Madrid, núm. 226, 13 de agosto de 1912, p. 363.

${ }_{25}$ Gaceta de Madrid, núm. 113, 23 de abril de 1913, p. 234.

${ }^{26}$ Gaceta de Madrid, núm. 204, 23 de julio de 1913, pp. 207-208.

${ }^{27}$ Gaceta de Madrid, núm. 231, 19 de agosto de 1913, pp. 436-437; núm. 251, 8 de septiembre de 1913, pp. 587-588.

${ }^{28}$ Nombramiento de 20 de mayo. Gaceta de Madrid, núm. 145, 25 de mayo de 1914, p. 511.

${ }_{29}$ Convocatoria de 31 de agosto. Gaceta de Madrid, núm. 256, 13 de septiembre de 1911, p. 680.

${ }^{30}$ AGA. 5398 (1). 32/7406. Cuestionario para las oposiciones a la cátedra de Arqueología, Numismática y Epigrafia, vacante en la Universidad de Barcelona. gía cristiana y la Edad Media como período esencial en la formación de la Historia de España. Su concepción de la Arqueología se basaba en planteamientos positivistas de las tipologías, inmuebles y muebles. Siguiendo el modelo de análisis definido por la Historia del Arte, se obviaba el estudio de las estructuras sociales, económicas, ideológicas o políticas correspondientes al material estudiado. No se incluyó ninguna referencia a la concepción de la Arqueología como ciencia, ni a la metodología de investigación o docente. Se resumía la arqueología prehistórica en tres temas que cubrían desde el Paleolítico a la Edad de los Metales. En cambio la protohistoria de la península ibérica se explicaba en nueve que abordaban desde la colonización fenicia y púnica a la cultura castreña, incluyendo referencias a los resultados de las intervenciones en Ampurias y Numancia, así como el debate sobre la antigüedad de las murallas de Tarragona a partir de los trabajos de Luis Pons d'Icart, Emil Hübner y Buenaventura Hernández Sanahuja.

Amorós Barra presentó un programa de ciento catorce temas para el apartado de Arqueología, veintidós para la Numismática y ocho para la Epigrafía ${ }^{31}$. Es muy similar al planteado por el tribunal por cuanto reserva más de la mitad de los temas a la Arqueología medieval. En el resto enuncia los contenidos de Prehistoria; Egipto; Caldea; Asiria; Persia; Heteos; Frigia y Licia; Fenicia, Chipre y Cartago; Hebreos, Grecia, Etruria, Roma y la Arqueología de la península ibérica. Los epígrafes dedicados a la arqueología protohistórica son significativos de ese concepto de docencia basado estrictamente en una descripción tipológica, sin referencias a las estructuras sociales estudiadas a partir de los objetos, como planteaba el tribunal. Las lecciones 55 a 57 (Tab. 3) son clara demostración de la concepción de la Arqueología no como parte integrante de la Historia sino como una enumeración descriptiva de materiales orientada a facilitar las clasificaciones museísticas.

Esta doble vía marcará la docencia del período comprendido entre 1915 y la Guerra Civil. Los catedráticos continuadores del modelo erudito, conocedores de los fondos bibliográficos y de los textos clásicos y medievales, determinarán una forma de ejercer la docencia y la investigación basada en el discurso acrítico y el aprendizaje nemotécnico. Los basados en el conocimiento de las corrientes teóricas europeas intentarán la renovación de la metodología y de los contenidos incorporando los resultados de las intervenciones arqueológicas. Es lógico que la principal transformación proceda de la Escuela de Arqueología de Barce-

31 AGA. 5398 (1). 32/7406. Expediente de las oposiciones a la cátedra de Arqueología, Epigrafía y Numismática de la Universidad de Barcelona en 1914. 
Lecciones de protohistoria en el programa de José Vicente Amorós Barra 1914

55 “Arte Ibérico. I. Primer grupo; épocas que comprende, artes que influyen. A) Arquitectura. Primer grupo.

Construcciones megalíticas existentes en las islas Baleares. Tipos principales. Construcciones ciclópeas. Segundo grupo. Tumbas de influencia fenicia. Escultura. Estatuas de influencia fenicia con carácter oriental. Artes menores. Cerámica. Vasos de influencia egea. Ensayos de coroplastia. Estatuillas de influencia fenicia. Toréutica. Figurillas, armas y objetos varios de influencia egea. Estatuillas de influencia fenicia. Objetos varios de influencia cartaginesa. Orfebrería”

56: "II. Segundo grupo: formación del arte ibérico; período histórico a que pertenece. Arquitectura. Castros y citanias. Templos, elementos, técnica y decoración; influencias. La casa ibérica. La calzada. Escultura. Influencias griegas. Fusión de estas influencias con las fenicias. Esculturas de carácter greco-fenicio. Policromía. Esculturas zoomorfas y antropomorfas de creación ibérica"

57: “Artes menores. Cerámica. Vasos de formas características, técnica y ornamentación. Toréutica. Estatuillas de marcado carácter ibérico. Técnica y arte. Armas. Orfebrería. Influencias que aparecen. Formas. Técnica y arte. III. Tercer grupo. Influencias romanas. Arquitectura. La casa. Escultura. Obras de carácter greco-romano. Obras de influencia romana. Artes menores. Toréutica, figurillas, fíbulas"

Tab. 3. Programa de oposiciones del candidato J. V. Amorós Barra, nombrado catedrático de Arqueología, Epigrafía y Numismática en la Universidad de Barcelona en 1914.

lona, cuyos integrantes, Pere Bosch Gimpera, Lluís Pericot García, Alberto del Castillo Yurrita y Elías Serra Ráfols, gracias a su formación práctica como arqueólogos de campo, conocían las implicaciones interpretativas basadas en el registro arqueológico. Sus temarios en las oposiciones a plazas de las universidades de Barcelona ${ }^{32}$, Santiago de Compostela ${ }^{33}$ y La Laguna $^{34}$, serán radicalmente diferentes, tanto en objetivos como en contenidos, de los anteriormente citados. Sin embargo no conseguirán imponer sus criterios entre el profesorado universitario, salvo Hugo Obermaier Grad quien, de forma autónoma en la Universidad Central, estructurará una docencia basada en el análisis del registro arqueológico a partir de su acceso a la cátedra el 15 de marzo de $1922^{35}$ por el procedimiento de nombramiento discrecional.

\section{EL CONCURSO A LA CÁTEDRA DE HISTORIA UNIVERSAL ANTIGUA Y MEDIA DE LA UNIVERSIDAD DE BARCELONA}

Para que el cambio se produjera debieron sucederse varios hechos, en principio no relacionados, pero que en el intrincado sistema de oposiciones español serían decisivos. Antonio Ballesteros Beretta fue de-

\footnotetext{
32 AGA. 32/7409. Legajo 5392-1. Programa presentado por el opositor Dr. D. Pedro Bosch Gimpera.

${ }_{33}$ AGA. 32/07424. Legajo 5399-2. Expediente de oposiciones a cátedras y auxiliarías de universidad. Año 1922. Cátedra de Historia Antigua y Media de España. Oposición libre. En relación a la oposición de Castillo, véase AGA. 6966/3-4. 32/13360. Tribunal de oposiciones a la cátedra de Historia Universal, vacante en la Universidad de Santiago.

${ }^{34}$ AGA. 5398 (2). 32/7422. Tribunal de oposiciones a las cátedras de Historia de España vacantes en la Universidad de Murcia y sección universitaria de La Laguna (Canarias).

${ }^{35}$ Gaceta de Madrid, núm. 107, 17 de abril de 1922, pp. 215-216.
}

terminante en el acceso de Bosch Gimpera a la cátedra, al conseguir en 1915 que la plaza de Historia Universal Antigua y Media quedara vacante, y apoyarle decisivamente en la repetición del concurso en 1916 (Gracia Alonso y Fullola Pericot 2016). La razón era la compresión por Ballesteros de la importancia de la Prehistoria y la Arqueología en la docencia de la Historia. En 1912, Ballesteros obtuvo por oposición la cátedra de Historia Universal Antigua y Media de la Universidad Central. En su temario dedicó sólo tres temas a la Prehistoria de los ciento diecisiete que lo componían $^{36}$, pero destacando la importancia de la Geología en el estudio de la Prehistoria; sus relaciones con la Paletnología; la diferenciación racial entre el Paleolítico y el Neolítico, o la evolución de la Humanidad durante las Edades de los Metales, para concluir con el empleo de los textos como elemento esencial del conocimiento de los períodos siguientes. La concepción de la interpretación de la Historia de su temario difiere radicalmente de la usual en las oposiciones hasta entonces. Separa las enunciaciones filosóficas y teológicas de las estrictamente científicas, situando el debate entre el positivismo y el materialismo, y la construcción del discurso narrativo, como el resultado de la interconexión entre los datos aportados por las diferentes ciencias auxiliares. Entre ellas, por vez primera, la Arqueología se incluye como determinante.

Las ideas de Ballesteros toparon frontalmente con el pensamiento del tribunal presidido por Manuel María del Valle, que acabó proponiéndole para la plaza de Madrid. El cuestionario propuesto por el tribunal ${ }^{37}$

\footnotetext{
${ }^{36}$ AGA. 5388 (1). 32/7402. Legajo 3588-2. Programa de Historia Universal Antigua y Media presentado por Antonio Ballesteros Beretta.

${ }^{37}$ AGA. 5388 (1). 32/7402. Legajo 3588-2. Cuestionario para los ejercicios de oposición a la cátedra de Historia universal, edades antigua y media vacante en la Universidad Central.
} 
era continuista con temas como: "La verdad y la certeza en la Historia", "El Diluvio de que nos habla Moisés en el Génesis, ¿es un hecho histórico o una leyenda? El Diluvio según las tradiciones de muchos pueblos antiguos" o "¿Son admisibles la relación del Génesis y las tradiciones de los pueblos que la confirman?". Además era retrógrado, puesto que las nomenclaturas empleadas en los relativos a Prehistoria y Protohistoria ("Período del Mamut", "Períodos de transición y del Reno") estaban periclitadas. Una experiencia que sin duda aplicó cuando, en su condición de juez, apoyó a Bosch Gimpera.

Ballesteros incidió durante el concurso en la necesidad de definir una metodología propia del trabajo histórico, situando en plano de igualdad los textos y el material procedente del registro arqueológico. Además, en su exposición sobre la metodología docente, criticó el sistema de clases magistrales defendiendo los nuevos métodos de enseñanza de la Historia, entre ellos los trabajos de seminario de las universidades germanas. Es lógico que viera en Bosch Gimpera, un arqueólogo formado en la Universidad de Berlín (Díaz Andreu 1996; Cortadella 2003) y defensor de sus ideas y metodología, el mejor candidato para intentar un cambio en la dinámica de las cátedras de Historia en una universidad española.

El acceso de Bosch Gimpera a la Universidad de Barcelona cambió radicalmente la concepción y los contenidos de la docencia de la Prehistoria y Protohistoria (Fig. 1) Se arrinconarán progresivamente las ideas creacionistas de otros catedráticos del centro como Martínez Ramírez, superando también los esquemas reductivistas de los miembros de la comisión que juzgó la oposición. Presidida por Rafael Altamira y Crevea e integrada por Ballesteros, Deleito, Francisco Matiola y el conde de Cedillo como vocales ${ }^{38}$, en el temario de 109 temas sometido a los opositores, sólo cuatro estaban dedicados específicamente a la Prehistoria. Sus títulos indicaban la escasa importancia que se les confería: "Orígenes de la ciencia prehistórica y principales fuentes para su estudio"; "Las razas prehistóricas"; "El arte y la habitación humana en los tiempos prehistóricos" y "Sepulturas prehistóricas. Origen del culto a los muertos". De esta visión centrada en el arte rupestre y en la arquitectura megalítica quedaban fuera los debates sobre el proceso de hominización y los estudios paleontológicos; la importancia del darwinismo y la oposición del creacionismo, así como las aportaciones de las escuelas Escandinava e Histórico-cultural de Arqueología que habían definido las secuencias tipológicas y crono-regionales de la

${ }_{38}$ AGA. 32/7409. Oficio del Consejo de Instrucción Pública al Ministerio de Instrucción Pública y Bellas Artes de 30 de julio de 1915.

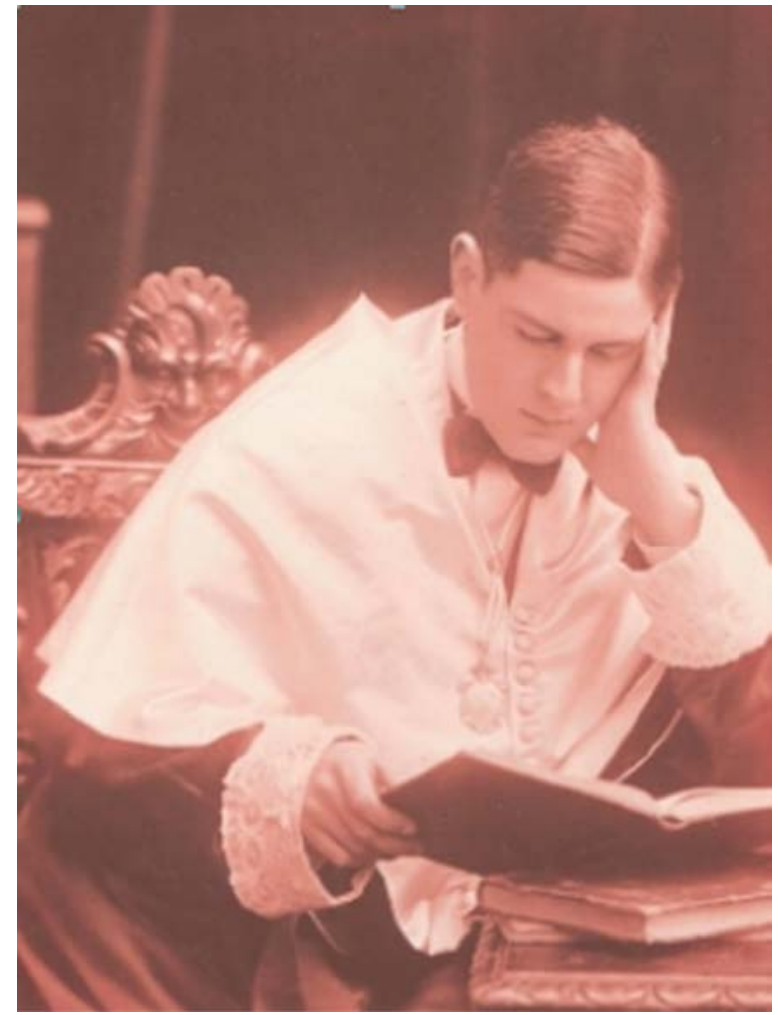

Fig. 1. circa 1916. Fotografía de estudio de Pere Bosch Gimpera, con solo 25 años, retratado con la toga y la medalla de catedrático (F. Grup de Recerca en Arqueologia Protohistòrica - Universitat de Barcelona Fondo GRAP-UB, Gracia Alonso 2011: 48, fig. 3, en color en la edición electrónica).

prehistoria europea durante un siglo. Es decir, se excluía la casi totalidad de la ciencia prehistórica moderna para centrarse en elementos que podían vincularse con la Historia del Arte y se explicaba la problemática de la evolución aplicando las tesis raciales de Joseph Arthur de Gobineau, en su Essai sur l'inégalité des races humaines (1853-1855). Determinantes en el siglo XIX eran ya muy cuestionadas en la fecha de la oposición dado el prolongado debate entre evolucionistas y creacionistas en España (Riera 1994; Pelayo y Gozalo 2012; Pelayo 2015).

El tribunal, además, mantenía temas ideológicos: "Carácter educativo de la Historia. Cuestión crítica sobre su fin patriótico y moralizador", "La Historia como Arte" y "La formación de las leyendas. El valor histórico de las mismas". Una explicación amable sería que los miembros de la comisión vinculaban el estudio de la Prehistoria y la evolución humana con las facultades de Ciencias y no con la Historia como se concebía en las facultades de Filosofía y Letras tras los cambios introducidos en 1900 por el ministro de Instrucción Pública y Bellas Artes Antonio García Alix. 


\section{Lecciones de Protohistoria}

"La primera Edad del Hierro. La época de Hallstatt en el centro de Europa: sus provincias. El Hierro en el norte de Europa. Ídem en Italia y en Grecia (época Geométrica)"

"Cronología de la primera Edad del Hierro. Etnografía. Germanos, Ilirios. La primera expansión céltica. Razas vecinas. Ligures e Iberos. Etnografía de Italia y del Mediterráneo en la primera Edad del Hierro"

"La segunda Edad del Hierro. La formación de la Cultura de la época de La Tène en el centro y el oeste de Europa. Su extensión por las penínsulas Ibérica e Itálica y hacia el este de Europa. La época de La Tène de los germanos.

Cronología y Etnografía. La segunda expansión céltica. El problema de la Etnografía española en esta época"

Bibliografía especializada sobre los Balcanes y el Egeo

Déchelette, Joseph. Manuel d'archéologie préhistorique, celtique et gallo-romaine, 1908-1914.

Hoernes, Moritz. Urgeschichte der bildenden Kunst in Europa, von den Anfängen bis um 500 vor Chr. (1898)

Kossinna, Gustav. Die Herkunft der Germanen. Zur Mehode der Siedlungsarchäologie, 1911.

Kossinna, Gustav. Die deutsche Vorgeschichte, eine hervorragend nationale Wissenschaft 1912.

Montelius, Oscar. Der Orient und Europa. Einfluss der Orientalischen Cultura uf Europa bis zur Mitte des Letzten

Jahrtausends V. Chr. 1889.

Montelius, Oscar. Kulturgeschichte Schwedens 1906.

Peet, Thomas. The Stone and Bronze Ages in Italy and Sicily, 1909.

Peet, Thomas. Rough Stone Monuments and their Builders, 1912.

Schmidt, Hubert. Troja-Mykene-Ungarn. Archologische Parallelen. 1904.

Schmidt, Hubert. Vorläufiger Bericht über die Ausgrabungen, 1909-10 in Cucuteni bei Jassy (Rumänien), 1911.

Schmidt, Hubert. Estudios acerca de los principios de la Edad de los Metales en España, 1915.

Tab. 4. Novedades bibliográficas, por orden alfabético, introducidas por P. Bosch Gimpera en sus ejercicios de oposición a la cátedra de Historia Universal Antigua y Media de la Universidad de Barcelona de 1916.

Sin embargo en 1916 ya desarrollaban sus trabajos el Centro de Estudios Históricos, la Comisión de Investigaciones Paleontológicas y Prehistóricas, y la Junta Superior de Excavaciones y Antigüedades, además de las estructuras académicas regionales, por lo que la ignorancia de los avances científicos no es admisible. La explicación más plausible debe vincularse con el concepto de la Historia y de su docencia en las universidades que defendían los miembros del tribunal que, no pudiendo evitar la inclusión de algunos aspectos esenciales como el arte, lo hacían desde una posición descriptiva, y no como un medio para explicar las estructuras sociales a las que estaba vinculado ${ }^{39}$. El claro negacionismo de la Prehistoria como ciencia se debía a que sus datos no podían emplearse como argumentos en la visión patriótica y nacional que se suponía debía construir la docencia en Historia.

En la oposición de 1916, Bosch Gimpera sabía por su decepcionante experiencia anterior que no podía incluir en el temario conceptos avanzados de investigación desconocidos en España. Sin embargo no re-

${ }^{39}$ AGA. 5392 (1). 32/7409. Cuestionario de Historia Universal (antigua y media) para las oposiciones a la Cátedra de la Universidad de Barcelona. Firmado por el presidente y el secretario del tribunal. nunció a estructurar, entre los 99 temas que presentó ${ }^{40}$, un apartado específico con 11 de "prehistoria", cuyos epígrafes muestran claramente la diferencia de conocimientos entre jueces y opositor (Gracia 2011: 149159). Las propuestas de Bosch son el resultado de la formación recibida en Alemania, y especialmente del conocimiento de las secuencias crono-tipológicas que definían la prehistoria europea desde el Paleolítico hasta la Edad del Hierro, como se demuestra en los epígrafes correspondientes a la Protohistoria (Tab. 4).

Su visión será menos enunciativa y más interpretativa, enfatizando las características sociales, ideológicas y económicas de las comunidades estudiadas. A la vez, introducía por primera vez en los temarios la problemática del proceso de hominización; la transición entre el Paleolítico y el Neolítico y sus facies regionales; las culturas eneolíticas y calcolíticas; la importancia de la Etnografía en el estudio de la Prehistoria y las secuencias regionales de las Edades del Bronce y del Hierro, con especial atención al área de los Balcanes y el Egeo (Tab. 4) por influencia de los trabajos de Montelius y Schmidt a los que añadirá las obras de Déchelette, Hoernes, Peet y Kossinna. Unirá así las ideas vincula-

40 AGA. 5392 (1). 32/7409. Programa presentado por el opositor Dr. D. Pedro Bosch Gimpera. 
das al difusionismo cultural y el migracionismo con las visiones nacionalistas de la investigación que definían los trabajos de Kossinna, en especial los conceptos de los focos originarios y los círculos culturales. Durante décadas aplicará todo ello en sus estudios con independencia de los condicionantes políticos que implicaran (Grünert 2002; Fernández 2009).

Bosch implementará dichas ideas desde su primera clase (2 de octubre de 1916) y su primera síntesis, L'Edat de la Pedra. En ella definirá su concepción de la Historia y la importancia de la investigación arqueológica: "el conocimiento científico puede obtenerse con monumentos escritos: es la Historia en sentido estricto $(. .$.$) en ocasiones debe buscarse estudiando los mo-$ numentos no escritos, las construcciones, las esculturas, todo tipo de objetos utilizados por el hombre, hasta los más humildes y que parecen más insignificantes como los fragmentos de cerámica o las piezas más simples de utillaje: es la Arqueología (...) existe un periodo en el que necesariamente hemos de emplear únicamente el estudio de los monumentos: la prehistoria" (Boch Gimpera 1916: 3-4). Pero Bosch no podrá sustraerse a las corrientes de la docencia de la época y mantendrá la importancia de los textos escritos sin cuestionar la forma de estudiar e interpretar las culturas del Próximo Oriente o las clásicas europeas. Reducirá el papel de la Arqueología al estadio de ciencia auxiliar para conocer las tipologías materiales, defendiendo su importancia decisiva sólo cuando faltaran textos escritos. La investigación en España mantendrá este planteamiento durante la mayor parte del siglo.

Bosch desarrollará una interpretación socio-cultural basada en la evolución cronológica de las tipologías materiales asociadas a las estructuras de poblamiento, siguiendo las pautas trazadas por el concepto de cultura enunciado por Montelius y continuado por Gordon Childe. En el estudio de la significación del arte rupestre, introducirá ideas de Henri Breuil, vinculando las representaciones figuradas con elementos mágicos propiciadores de la caza y la fecundidad desde una perspectiva más narrativa que simbólica. Los planteamientos docentes e investigadores de Bosch Gimpera cambiaron la investigación prehistórica en Cataluña desde el inicio de su seminario en la Universidad de Barcelona en el otoño de 1916, chocando con las rutinas anquilosadas de sus colegas en la Facultad de Filosofía y Letras.

\section{EL CURSO MONOGRÁFICO SOBRE CULTURA IBÉRICA DE 1917}

La forma como Bosch Gimpera comprendía los procesos históricos se aprecia sobre todo en el ámbito de la protohistoria peninsular. La analizamos a partir de los apuntes tomados por Lluís Pericot ${ }^{41}$ en 1917 (Fig. 2) en el monográfico sobre Cultura Ibérica que impartió dentro del Programa de Cursos complementarios y de investigación ${ }^{42}$, organizado por diversos profesores de las facultades de Filosofía y Letras y de Ciencias de la Universidad de Barcelona, como Antoni Rubió i Lluch, Telesforo de Aranzadi Unamuno y Jaume Serra Hunter, comprometidos con el proceso de renovación de la docencia universitaria. Este se plasmará en 1918 en las conclusiones del Segundo Congreso Universitario Catalán, base del profundo desarrollo pedagógico que alcanzará la Universidad de Barcelona durante la Segunda República, uno de cuyos principales artífices será Bosch Gimpera, rector entre 1933 y 1939 (Gracia 2015b).

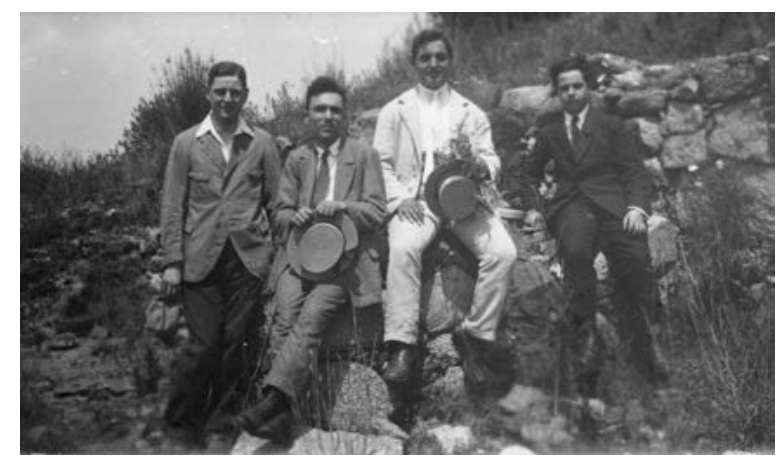

Fig. 2. circa 1917. Excursión de prácticas al poblado ibérico de Puig Castellar (Santa Coloma de Gramanet, Barcelona). De izquierda a derecha Pere Bosch Gimpera, junto a alguno de sus alumnos, Salvador Roca Llejós, Lluís Pericot (con traje blanco) y un tercero no identificado (Fondo Familia Fullola-Pericot, Gracia Alonso 2011: 160, fig. 8).

Bosch partió de los resultados de su tesis doctoral, El problema de la cerámica ibérica, redactada bajo la supervisión de Manuel Gómez Moreno y defendida el 11 de octubre de 1913 en la Universidad Central ante un tribunal formado por Eduardo Hinojosa, Antonio Ballesteros, Antonio Vives y José Ramón Mélida (Bosch Gimpera 1913). En la misma, siguiendo la metodología de trabajo aprendida de Schmidt (Cortadella 2003:

\footnotetext{
${ }^{41}$ LA CULTURA IBERICA. Curset donat á l'Universitat de Barcelona per el Dr. Dn. PERE BOSCH $i$ GIMPERA, catedratic de l'asignatura de Historia Universal antiga i mitja. Apunts presos per en Lluis Pericot $i$ Garcia. Original mecanografiado. Se ha mantenido la grafía original. UB. Colecciones Especiales. Fondo Bosch Gimpera-Pericot.

${ }^{42}$ Archivo Histórico de la Universidad de Barcelona, Barcelona (AHUB). Programa de los cursos complementarios y de investigación organizados por profesores de las facultades de Filosofia y Letras y de Ciencias para el ler semestre de 1917. Guies d'assignatures històriques de la Universitat de Barcelona (consulta 8 de octubre de 2020) diposit.ub.edu/dspace/handle/2445/122957
} 
XLVIII-XLIX), y pese a las reticencias personalistas de Mélida y Gómez-Moreno, revisó la problemática cronológica y territorial de las producciones cerámicas atribuidas a la cultura Ibérica. Rebajó su cronología, desestimó las relaciones con las producciones micénicas, y definió sus características formales. Concluyó que su origen debía situarse en el sur y el sudeste peninsular, extendiéndose posteriormente por el levante, el nordeste y el sur de Francia, hasta alcanzar el valle del Ródano. En una tercera fase, por la ruta del Ebro, se habría difundido en Aragón y la Meseta. Definió cuatro regiones tipológicas específicas: la primera el sudeste, las Baleares, Cataluña y el sureste francés; la segunda Andalucía y el valle del Guadalquivir; la tercera el valle del Ebro en relación con la Cataluña occidental, y la cuarta Castilla, cuyo territorio dividía en dos grupos: el meridional en el valle del Jalón, y el septentrional en el alto valle del Duero. Cometió errores como caracterizar como ibéricas a las cerámicas numantinas, pero introdujo una forma de estudio que consideraba los materiales muebles como documentos históricos, y no piezas artísticas. Su tesis se publicó de inmediato en Berlín (Bosch Gimpera 1913). Fue bien acogida en los medios científicos alemanes, satisfechos con este trabajo sobre la península ibérica que seguía la metodología germana, donde un investigador formado en sus aulas desmontaba sistemáticamente las tesis previas sobre las cerámicas ibéricas sostenidas por Pierre Paris (19031904) y Salomón Reinach (1905: 156-160), en especial las referidas a la vinculación micénica. La Comisión de Investigaciones Paleontológicas y Prehistóricas publicaría la versión castellana de un texto (Bosch Gimpera 1915) del que arrancarán dos de sus líneas de trabajo: la clasificación crono-tipológica de la cerámica ibérica, y la ausencia de una unidad política y cultural durante la protohistoria peninsular. Trasladará estas ideas al ámbito político con repercusión antes, durante y después de la Guerra Civil.

Según los apuntes de Pericot el curso de Bosch Gimpera se dividió en cinco temas o clases (Tab. 5) que supusieron una ruptura por sus contenidos y por la metodología docente. Alejado del concepto de busto parlante que peroraba contenidos incuestionables, incluyó proyecciones, fotografías, planimetrías y dibujos de materiales, además de emborronar con lápices de colores mapas de la península ibérica para mostrar la ubicación de los yacimientos (Fig. 3 arriba), la situación de las tribus citadas en los textos clásicos o las rutas de las migraciones (Fig. 3 abajo). Incitaba así la participación crítica de sus alumnos a quienes ani-

\section{Pere Bosch Gimpera, Programa del Curso monográfico "Cultura ibèrica", Universidad de Barcelona, 1916}

I. Etnografía de la península Ibérica hacia el año 500 a.de J.C.: los iberos y los pueblos vecinos. Las colonizaciones: fenicios, griegos, cartagineses. La conquista romana

II. La cultura de los colonizadores: los fenicioscartagineses; las necrópolis de Gades, Ibiza, Villaricos. La cultura griega en España: Emporion; la ciudad y sus períodos; los hallazgos

\section{Hugo Obermaier, Programa de la asignatura "Historia primitiva del hombre" Universidad Central, Madrid, 1930}

XXXVII, España. La primera edad del Hierro: sus distintos aspectos en Almería, el centro de España, en Cataluña y el norte. La segunda edad del Hierro: la civilización posthallstática de Portugal, del centro de la Península y de Cataluña. Su persistencia en los castros del norte de Portugal y de Galicia hasta la época romana

XXXVIII, La cultura ibérica: su origen, sus regiones y cronologías respectivas. La cultura ibérica del S.E. de España y de Andalucía. La cultura ibérica de los siglos V-IV en el reino de Valencia, en el bajo Aragón y en Cataluña. La cultura ibérica del sur de Francia

XXXIX: La cultura ibérica del siglo III de la costa de Cataluña y de los grupos dependientes del Ebro. La cultura ibérica del siglo III del centro de España y en Portugal. problemas de la cultura Ibérica de la costa: la plástica, la cerámica pintada, las espadas. Cronología

IV: La cultura Ibérica en la región del Ebro. Sus períodos. Las primeras estaciones del Bajo Aragón. El siglo III a.de J.C.: los poblados y su material. Las importaciones helenísticas y las relaciones con otras culturas de Europa

V: La cultura Ibérica del centro de España. Sus primeras manifestaciones en las necrópolis de la cuenca del Jalón. Numancia. La cultura Ibérica en la época romana.
XL: Las distintas colonizaciones: fenicios, griegos y cartagineses. Sus periodos y restos arqueológicos

XLI: La civilización ibérica en general: poblados y fortalezas. Armas y utensilios. Cerámica. Arte. Santuarios; ideas religiosas. Sepulcros y prácticas funerarias

Tab. 5. Comparación entre el contenido de la Protohistoria en la docencia de Pere Bosch Gimpera (UB. Colecciones Especiales. Fondo Bosch Gimpera-Pericot) y Hugo Obermaier (Sánchez 2001; Mederos 2010-2011). 

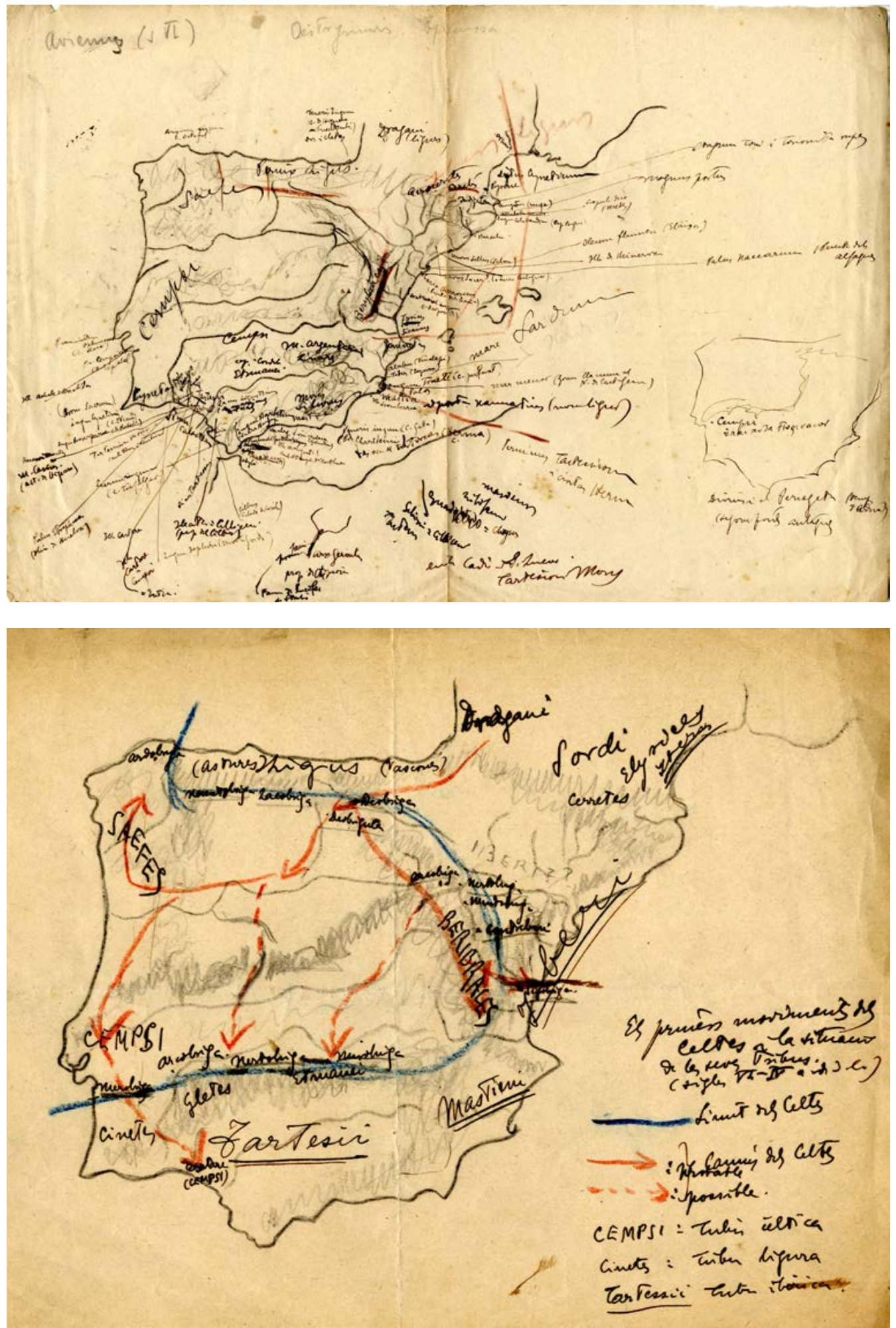

Fig. 3. Dibujos realizados por Pere Bosch Gimpera para sus clases. El superior sitúa los topónimos citados en la Ora Marítima de Avieno y el inferior los desplazamientos de las tribus celtas (Fondo UB Universitat de Barcelona). En color en la edición electrónica.

Trab. Prehist., 77, N. ${ }^{\circ}$ 2, julio-diciembre 2020, pp. 237-254, ISSN: 0082-5638

https://doi.org/10.3989/tp.2020.12254 
maba a cuestionar las explicaciones, aplicando un modelo docente que había aprendido en Alemania, pero que resultaba totalmente novedoso en la Universidad de Barcelona. No es de extrañar que un entusiasta grupo de estudiantes se incorporase a sus clases en 1916, configurando el núcleo de la futura Escuela de Arqueología de Barcelona (Gracia 2011).

Bosch Gimpera desarrollará el primer tema a partir del análisis etnográfico de los ligures, celtas e iberos que consideraba habitaban la península ibérica a finales del siglo VI a. C. Su primera aproximación se basaba en los textos de Hesíodo, Estesícoro, Herodoto y Hecateo y para la diferenciación entre celtas y ligures en los de Éforo y Eratóstenes, pero cuestionará dichas informaciones cuando carezcan de corroboración arqueológica. Cifró la entrada de los celtas en la península hacia el 600 a. C. como resultado de una corriente migratoria centroeuropea analizada mediante las tipologías materiales de las necrópolis hallstátticas en Francia y España. Concluyó que la expansión se produjo a través de los Pirineos occidentales hasta alcanzar las cuencas del Duero y Tajo y, posteriormente, el sur de Portugal. Negará la extensión a Cataluña indicando que los iberos se asentarían en la región tras la presencia de los celtas en el interior, llegando hasta el sur de Francia, donde se mezclarían con los ligures. El movimiento poblacional celta se habría producido hacia el 400 a. C. Su expansión a la península itálica, Grecia y Asia Menor habría producido, siguiendo a Diodoro Sículo, el retroceso de los iberos al sur de los Pirineos y la entrada de los galos en el nordeste. Timeo y Eratóstenes servirán de base para explicar la situación geográfica de los celtas, confinados en el Algarbe y Galicia (celtici); el área de Logroño (berones), y las estribaciones de Sierra Morena (germani). Las poblaciones celtibéricas serían el resultado de la invasión por los iberos de la Meseta y la asimilación de las estructuras locales, dado que el nombre "celtíberos" significaría "iberos en tierra de celtas", y sus costumbres serían las de los iberos, llegando a definir a cántabros y astures como iberos, o incluso ligures.

El migracionismo propio de la corriente históricocultural dominante en la arqueología europea en el periodo entre siglos está presente en sus explicaciones. No considera a iberos y ligures miembros del grupo cultural indo-germano; no admite las teorías sobre su origen caucásico; explica las tesis sobre su posible origen norteafricano y la vinculación con los camitas; admite una procedencia africana de los ligures, y afirma que habrían llegado a controlar todo el occidente de Europa. Fija la colonización fenicia en el 1.100 a. C. a partir de los textos griegos, defendiendo también la problemática bíblica de las naves de Tarshish, aunque niega las tesis de Siret (1913) sobre una cronología anterior. La relación con los iberos es pacífica hasta el siglo VIII a. C. en que intentarían dominarlos pero, tras la caída de Tiro, los iberos se habrían impuesto y formado un imperio fuerte en el que destacaría la figura de Argantonio. Es decir, Bosch incluye a Tarteso en la cultura Ibérica. Explica la presencia cartaginesa para establecer la importancia de los tratados entre Roma y Cartago, la ocupación de las Baleares, la expansión Bárquida, el inicio de la Segunda Guerra Púnica y el inicio de la presencia romana, posibilitada por el apoyo de los colonos griegos. Éstos se habrían establecido ya en el siglo VII a. C. tras los primeros viajes samios descritos por Herodoto, y continuaron con la expansión focea desde Masalia y la fundación de las colonias de Emporion, Rhode y Mainake. Fija el inicio de la decadencia colonial en las consecuencias de la batalla de Alalia - un tema que será recurrente en su bibliografía posterior (Bosch Gimpera 1932; 1975)-, para concluir que la influencia comercial y cultural griega sobre los iberos fue mucho mayor que la ejercida por los cartagineses.

Para explicar las colonizaciones empleará exclusivamente la documentación arqueológica, detallando las excavaciones de Pelayo Quintero Atauri en los yacimientos gaditanos, con especial atención a sus informes sobre Punta de la Vaca (Quintero 1916). Vinculará el sarcófago antropoide descubierto en 1887 con el arte sidonio y el asirio, extendiéndose en los elementos iconográficos de origen egipcio o griego de los materiales documentados. Establece así otra de sus pautas docentes: la interrelación entre estructuras sociales mediterráneas aplicando el concepto de koiné que sus discípulos retendrán y trasladarán como un referente básico. Criticará las tesis sobre la expansión de los púnicos a la Celtiberia $\mathrm{y}$, al analizar el yacimiento de Baria (Villaricos) a partir de las intervenciones de Siret en 1908, propondrá interpretarlo como un asentamiento ibérico que aúna piezas de procedencia cartaginesa como los amuletos con representación de Bes y los huevos de avestruz decorados con importantes importaciones griegas de los siglos VI y V a. C. como elemento cultural determinante. Indica su similitud con las tipologías cerámicas halladas en otros poblados ibéricos en los que destacan las "espadas o sables curvos" -no emplea el concepto "falcata" acuñado por Fernando Fulgosio- y las "espadas celtas de antenas" que considera precedentes de las "espadas cortas de antenas", a su juicio, propias de la cultura ibérica. Se basó en la monografía de Vives Escudero (1917) para describir la necrópolis de Puig des Molins y los yacimientos ibicencos de Isla Plana, Cueva d'Es Cuieram. Asigna a esta última una cronología comprendida entre el siglo $\mathrm{V}$ a. C. y época romana y la vincula con el culto a Astarté. Describe la tipología de las tumbas y las características del material. Considera las piezas de origen púnico idénticas a las distribui- 
das en toda la costa oriental hasta Ampurias, por lo que avanzó la extensión del comercio púnico en el levante peninsular. Obviamente, el grueso de la clase estuvo dedicado al análisis de los resultados de las intervenciones de la Junta de Museos de Barcelona y el Institut d'Estudis Catalans desde 1908 en la colonia focea de Ampurias bajo la dirección de Josep Puig i Cadafalch. Detallaba las estructuras arquitectónicas, los hallazgos escultóricos -la estatua de Asklepio sería producto del arte provincial griego y la cabeza de Afrodita de tipo praxiteliano-, y las tipologías materiales griegas -siguiendo a Frickenhaus (1908)- y romanas con especial atención a las cerámicas de barniz negro de época republicana e imperial.

En la tercera clase analizó las estructuras poblacionales ibéricas a partir de las tribus para establecer sus diferencias, criticando la propuesta unificadora de Pierre Paris. Argumentó el mayor desarrollo de las comunidades costeras por el impacto del contacto comercial y colonial. Partiendo de su tesis doctoral, dividió el territorio en cuatro regiones: sudeste, Andalucía, cuenca del Ebro y Celtiberia, subdividida a su vez por la cuenca del Jalón. Consideraba un modelo poblacional basado en acrópolis fortificadas "verdadero prodigio de arquitectura militar", que englobarían viviendas pluricelulares y estructuras de aprovisionamiento de agua como construcciones principales, describiendo los resultados de las intervenciones en El Castellar (Meca), El Amarejo (Bonete), San Antonio (Orihuela) y La Alcudia (Elche), primando los resultados de los trabajos de Paris (1903-1904) en las tres primeras, y criticando las de Eugène Albertini $(1906,1907)$ en la última, indicando que sólo se disponía de reducidas series cerámicas además del busto de la Dama de Elche. No obstante, analiza la cultura material en su conjunto, estableciendo tipologías formales basadas en la funcionalidad, y en tres categorías decorativas: geométricas, florales y zoomorfas. Los trabajos Engel y Paris (1906) fundamentarán su análisis de la región andaluza, primando las intervenciones en Osuna. Describirá sus estructuras arquitectónicas, la tipología cerámica y, de forma extensa, los conjuntos escultóricos, con especial atención a las características del armamento representado.

Bosch Gimpera caracterizará después dos grupos de santuarios: sudeste y Andalucía, ejemplificando el primero en el Cerro de los Santos (Montealegre del Castillo) -a partir de los trabajos de Juan de Dios de la Rada y Delgado (1875) y Julián Zuazo Palacios (1915) - y el segundo en el Castillar de Santisteban (Despeñaperros) a partir de los de Raymond Lantier (1917) y Juan Cabré. Describe y organiza las categorías de exvotos, empleando los elementos iconográficos para explicar las características de las estructuras sociales, además de comentar la colección de exvotos donada al Museo Arqueológico Nacional por Antonio Vives Escudero. Sin embargo, no recurrirá a los trabajos de Cabré e Ignacio Calvo (1916) en El Collado de los Jardines. Centró el análisis de las necrópolis en las de Almedinilla, Fuente Tójar y Archena, señalando las características de los ajuares y la iconografía de la cerámica, las armas y la escultura -incluyendo también los materiales de los museos de Madrid y Barcelona-. Basándose en los estudios de Juan Rubio de la Serna (1888), describió los tesoros de Jávea y Tivissa, y caracterizó la necrópolis de Cabrera de Mar y el poblado del Puig Castellar (Santa Coloma de Gramanet), como ejemplos representativos de la fase final de la cultura ibérica,

Tras la enunciación de datos, Bosch incidió en que la falta de excavaciones metódicas impedía un correcto análisis de la cultura ibérica, pero concluyó que la cronología de los materiales presentados era posterior al siglo $\mathrm{V}$ a. C. y anterior a la conquista romana. Recalcó la importancia de las estratigrafías de Ampurias para la datación, por asociación, de las producciones ibéricas, y la necesidad de estudiar su evolución formal y estilística junto con la de la cerámica griega de los siglos V y IV a. C. en el sudeste y el sur para analizar los yacimientos. Descartó la influencia de la cerámica púnica en la ibérica, vinculando las figuras zoomorfas de la pintura sobre cerámica con los prototipos griegos y orientalizantes del siglo VI a. C. Descartó que estuviera influida por las producciones micénicas o las del Geométrico, cuestionando las tesis de Paris y Mélida. Definió el armamento ibérico a partir de los tipos de La Tène. Descartaba un origen egeo de la espada curva -a la que consideraba como "el arma nacional"-, empleando el estudio de Horace Sandars (1913) para analizar sus vinculaciones con los cuchillos curvos y asignarle un origen hallstáttico. Por último, aprovechó los movimientos célticos para explicar las tipologías de las fíbulas y las hebillas de cinturón del siglo III a. C.

Bosch (1923a, 1923b) reservó el cuarto tema para explicar sus propias intervenciones en los poblados ibéricos del Bajo Aragón (Bosch 1915-1920), cuyas características diferenció de los de la Meseta y el sudeste. Los trabajos pioneros de Pablo Gil y Gil en La Zaida (Puebla de Híjar), describiendo los materiales conservados en los museos de Barcelona y Zaragoza, así como las exploraciones de Santiago Vidiella Jassà y Cabré en Calaceite precederían al interés y la extensión de las intervenciones desarrolladas por el IEC desde 1914 en la zona (Gracia 2019), en especial en los poblados de La Gessera (Casseres) y San Antonio el Pobre (Calaceite) que él mismo dirigió (Gracia 2011). A ellos se sumaban el estudio del Tossal de les Tenalles (Sidamunt) a cargo de Josep Colominas Roca y Agustí Duran i Sanpere (1923). Definía tres fases

Trab. Prehist., 77, N. ${ }^{\circ}$ 2, julio-diciembre 2020, pp. 237-254, ISSN: 0082-5638

https://doi.org/10.3989/tp.2020.12254 
entre los siglos V al III a. C. Los poblados de Les Escondines Altes, Les Escondines Baixes y San Cristóbal (Mazaleón) y Tossal Redó y El Vilallonc (Calaceite) ejemplifican la primera (siglo $\mathrm{V}$ y primera mitad del siglo IV a. C.) con construcciones en piedras no desbastadas calificadas como "muy primitivas", cerámica a mano de factura tosca decorada con impresiones digitales e incisiones, y producciones metalúrgicas simples. Destacó en Tossal Redó las primeras series de cerámica a torno sin decorar, el urbanismo avanzado basado en el modelo de calle central y viviendas seriadas adosadas al perímetro de la muralla, y las producciones metálicas en bronce y hierro, describiendo y clasificando los diferentes tipos de objetos, desde los botones a las fíbulas y los broches de cinturón. La segunda fase (segunda mitad del siglo IV a. C.) está representada por el poblado de La Gessera (Caseres). Se caracterizaría por el desarrollo de las producciones a torno y la influencia, según Bosch, de las producciones griegas en sus tipos. El tercer período (siglo III a. C.) englobaría los poblados de San Antonio el Pobre (Calaceite), Mas de les Madalenes (Cretas), Piuró del Barranc Fondo (Mazaleón), La Tallada y Palermo (Caspe), La Zaida, Tossal de les Tenalles, Tossal del Mort (Tàrrega). Explicará especialmente Guissona a partir del primero, revisando las aportaciones de Josep Pijoan (1908), Julio Furgús (1909), Cabré (1908) y Vidiella (1908) junto a los miembros del Boletín de Historia y Geografia del Bajo Aragón, a las que sumará las realizadas por el IEC. Describirá en detalle la topografía y la planimetría del yacimiento, las características constructivas y las tipologías materiales. Amplió los datos con el estudio de los poblados de La Zaida y de Caspe, así como de piezas como la coraza y el thymiaterion de Les Ferreres (Calaceite), y las estelas de Palermo y San Marcos de Chiprán. Prestó especial atención a las influencias hallstátticas partiendo de los trabajos Déchelette y a la distribución de las cerámicas helenísticas, para concluir que la cultura ibérica en el Bajo Aragón alcanzaría su apogeo en el siglo III a. C., más tarde que en el área de la costa.

La quinta clase estuvo dedicada a los yacimientos del área de Guadalajara, Soria y Burgos, definiendo tres fases: las necrópolis de tipo hallstático que se prolongaban hasta la introducción de los materiales tipo La Tène $\mathrm{C}$; los poblados ibéricos caracterizados con las producciones típicas de dicha cultura; y los yacimientos romanos con materiales que mostraban la continuidad de la etapa anterior ejemplificados en Tiermes y Osma. Bosch criticará los trabajos del marqués de Cerralbo $(1909,1913)$ en las necrópolis de Soria y Guadalajara negando su condición de ibéricas y argumentado que se trataba de yacimientos celtas con inclusión de materiales ibéricos a partir del siglo III a. C.
Hará lo mismo con las ideas de Mélida (1906) sobre la influencia de las cerámicas micénicas y las series del Dípilon en las producciones numantinas. Las cifra por asociación con otros materiales entre los siglos III y II a. C., antes de describir en detalle los resultados de las intervenciones de Schulten (1914) para demostrar las influencias ibéricas a partir del siglo III a. C., y los de los trabajos de la comisión española para explicar el urbanismo y las tipologías materiales de las etapas celtibérica y romana (Mélida 1916). Vincula las piezas metálicas en hierro y en bronce con las producciones de La Tène. En cambio, siguiendo las conclusiones de su tesis, interpreta las cerámicas como ibéricas, si bien las decoraciones zoomorfas y antropomorfas serían propias de la zona donde "faltan las estilizaciones vegetales y los ornamentos mixtos. Se trata pues de un arte regional con predominio de las decoraciones animales, humanas y geométricas. Es un arte bárbaro mucho más degenerado que las formas parecidas de Aragón (y en esta región el arte no es ni con mucho lo que es en el sur y el este". Tras explicar la campaña de Escipión Emiliano en el 133 a. C., describió las intervenciones de Schulten en los campamentos de circunvalación. Criticó las tesis de Manuel González Simancas sobre la posibilidad de que dichos recintos fuesen barrios numantinos, y las ideas de Santiago Gómez Santa Cruz (1914) sobre su finalidad, alineándose con las tesis de Schulten en la interpretación de las excavaciones en Renieblas. Completará el análisis con el comentario de las intervenciones del marqués de Cerralbo en Arcóbriga (Monreal de Ariza) y de Ignacio Calvo (1916) en Clunia; los trabajos de Gómez-Moreno (1900-1901, 1901-1903, 1908) sobre posibles yacimientos ibéricos en Salamanca, Zamora y León; de Mélida afirmando la existencia de poblados ibéricos en Extremadura y de piezas cerámicas en Portugal, a las que considera de influencia o procedencia andaluza, y de Ignacio Calvo (1914) en Galicia. Antes de dar por finalizada la docencia, Bosch Gimpera comentó a sus alumnos la publicación de Sandars (1914) sobre el tesoro de Mogón (Villacarrillo) cuyas piezas comparó con las de Tivissa, además de los resultados de las exploraciones de Colominas en la provincia de Castellón, que fijó en los siglos V y IV a. C.

\section{LA INFLUENCIA DE LOS CONTENIDOS DOCENTES Y LA METODOLOGÍA DE BOSCH GIMPERA}

El impacto de la docencia de Bosch Gimpera entre sus alumnos se muestra en el examen de grado realizado por Lluís Pericot el 7 de junio de 1918 ante un tribunal integrado por Martínez Ramírez, Eduardo Pérez Agudo y el propio Bosch (Gracia 2017: 55-57). 
Desarrolló, por sorteo, el tema: Concepto de la Prehistoria, Estaciones prehistóricas ${ }^{43}$, viéndose obligado a dar una visión canónica para complacer al presidente de la comisión, según la cual "la prehistoria, llamada también protohistoria por algunos, no es más que una parte de la historia de la humanidad en la que el método arqueológico es sólo aplicable por la carencia de testimonios escritos de aquella época remota". Sin embargo, citó en su exposición las obras de Lartet, Piette, Cartailhac, Evans, Ficher, Montelius, Reinecke, Schuchardt, Kossinna, Schmidt, Déchelette, Boule, Breuil y Obermaier. Pericot demostraba así el peso alcanzado por la Prehistoria en la Universidad de Barcelona en sólo dos años gracias a Bosch Gimpera, quien en sus clases citaba también los trabajos de Vilanova y Piera, Rada y Delgado, Cazurro, Vidal Carreras, Mélida, Vives Escudero y Fita.

Los cambios serán lentos, pero sus ideas se irán extendiendo entre los sectores entonces más progresistas en la Universidad de Barcelona. El medievalista Antonio de la Torre y del Cerro, en su programa de Historia de España para el curso 1926-1927 ${ }^{44}$ entregó una relación de 97 temas divididos en seis apartados claramente decantado hacia la Edad Media con treinta y siete, frente a dos para la Prehistoria y tres para la Protohistoria. Su ortodoxia a partir de la romanización, contrasta con la importancia dada a la investigación arqueológica en los primeros, donde plantea las divisiones tipológicas del Paleolítico y los principales yacimientos y, a partir de ellos, la interpretación de las estructuras sociales para tratar de "la vida humana". La importancia historiográfica de los textos escritos como base del discurso se muestra en los temas dedicados a la Protohistoria. En el primero, las colonizaciones, la estructura es canónica: fenicios, griegos y púnicos, mientras que el segundo, centrado en "las instituciones y la cultura" de los pueblos prerromanos, el tratamiento es igual de canónico, basándose en los datos contenidos en los textos greco-latinos sobre los siglos II-I a. C., para extrapolarlos a los diversos territorios a partir del siglo VI a. C. Sin embargo, realiza una interesante distinción en el tercero, dedicado a los "pobladores de la península en el período prerromano", al dividir la explicación de la Edad del Hierro y la cultura Ibérica en dos bloques comparativos: los estudios derivados de la investigación arqueológica y del análisis de los textos, recurso propio de la metodología de Bosch Gimpera.

\footnotetext{
${ }^{43}$ AHUB. Expediente Lluís Pericot. 01.4253. Examen de Grado de Licenciado. Tema 57.

${ }^{44}$ AHUB. Historia de España. Programa. Barcelona, 1926. Guies d'assignatures històriques de la Universitat de Barcelona (consulta 8 de octubre de 2020 ) diposit.ub.edu/dspace/handle/2445/47777
}

Que algunos catedráticos de la Universidad de Barcelona incluyeran cambios conceptuales no implica que todos lo hicieran. Francisco Nabot Tomás, que abría y cerraba el programa de su asignatura Historia de España en el curso 1934-1935 con cristogramas (JHS y AMGJC en cada caso) ${ }^{45}$, ignoraba totalmente la Prehistoria, iniciando las explicaciones con la colonización fenicia y una referencia a "los primeros pobladores de España y donde se establecieron" ${ }^{46}$, antes de centrarse en la romanización. Esta visión retrógrada de la concepción de la Prehistoria perdurará tras la Guerra Civil, cuando el catedrático de Historia Universal Moderna y Contemporánea entre 1941 y 1943, Joaquín José Baró Comas, explique a sus alumnos que la Historia empezaba con Adán, Eva y los hijos de Sem, Cam y Jafet, planteamiento ranciamente creacionista muy del agrado del nacionalcatolicismo dominante (Bosch Gimpera y Olivar 1978: 155, 183-184).

La comparativa más lógica es la docencia de Obermaier en la Universidad Central dada su influencia y prestigio (Mederos 2010-2011; Sánchez 2001). En 1930, su programa de la asignatura "Historia primitiva del hombre" incluía cinco temas sobre la protohistoria peninsular (Tab. 5). La influencia de los trabajos de Bosch Gimpera sobre el planteamiento de Obermaier es clara puesto que define un sistema de análisis territorial ya presente en la tesis de Bosch defendida en 1913. Sin embargo hay notables diferencias. Obermaier continuaba calificando como ibéricas a las estructuras sociales y territoriales celtibéricas del centro y el occidente peninsular. Este error que Bosch había cometido mientras realizaba su estudio y mantenía en el curso impartido en 1917, ya lo había subsanado. Lo demuestra el contenido de la docencia sobre arqueología española impartida por Lantier en la École $d u$ Louvre, basada esencialmente en los trabajos de su amigo Bosch Gimpera (Gracia 2015a). Obermaier, además, no integra la información arqueológica y la textual en un único discurso expositivo. Diferencia la baja época de la cultura ibérica -a partir del siglo III-, y trata la problemática de las colonizaciones desde una perspectiva separada del proceso de conformación de las estructuras sociales protohistóricas para, en último término, explicar la investigación arqueológica a partir de los tipos de yacimientos.

Los prehistoriadores e historiadores de la antigüedad sostenían una visión, marcada por la diferenciación conceptual entre Prehistoria/Protohistoria e Historia.

\footnotetext{
${ }^{45}$ En el primer caso se trata de la referencia a Jesucristo o bien "Jesús, Hijo y Señor". En el segundo el significado es "A la Mayor Gloria de Jesucristo".

${ }^{46}$ AHUB. Programa de Historia de España. 2. ${ }^{\circ}$ Grado. 1934. Guies d'assignatures històriques de la Universitat de Barcelona. (consulta 8 de octubre de 2020 ) diposit.ub.edu/dspace/handle/2445/63333
} 
Propugnaban que el proceso colonial debía analizarse desde una perspectiva "histórica" como parte de un sistema general analizado en función de los textos escritos, y no desde una vertiente "prehistórica" que tuviera como eje fundamental la explicación del registro arqueológico. Por el contrario, Bosch Gimpera ya optaba por definir las bases de la etnología protohistórica peninsular y analizaba la influencia de las colonizaciones en el proceso de formación de los sistemas socio-territoriales del Ibérico antiguo y el Ibérico pleno desde una perspectiva esencialmente arqueológica. También era esencialmente arqueológico el análisis de las secuencias poblacionales ibéricas, por lo que puede afirmarse que los planteamientos de Obermaier estaban claramente desfasados.

En conclusión, los intentos de Bosch por conferir un peso esencial al resultado de las intervenciones arqueológicas en la docencia en Protohistoria sólo tendrán influencia entre sus discípulos directos. En la mayoría de las cátedras universitarias españolas de Historia y Arqueología, la influencia de la docencia basada en los textos y las pautas de la Historia del Arte continuarán siendo preeminentes. La Guerra Civil supondrá, sin embargo, la ruptura en la docencia sobre Protohistoria en la Universidad de Barcelona durante varias décadas, al menos de forma específica, por cuanto los contenidos de las asignaturas impartidas por Almagro Basch y Pericot serán esencialmente generalistas como correspondía a los programas de la época. Hasta el retorno a Barcelona de Juan Maluquer de Motes en 1960 la docencia y la investigación sobre protohistoria peninsular y la cultura ibérica en particular no recuperan el rango de importancia que habían tenido durante la etapa de Bosch Gimpera.

\section{BIBLIOGRAFÍA}

AA. VV. 2015: L'École des Chartes et sa "grande guerre": servir la nation par la politique et l'histoire. École des Chartes. París.

Albertini, E. 1906: "Fouilles d'Elche". Bulletin Hispanique VIII: 333-362.

Albertini, E. 1907: "Fouilles d'Elche". Bulletin Hispanique IX: 1-17.

Almagro Gorbea, M. 2007: "La Real Academia de la Historia y la Escuela Superior de Diplomática”. En 150 aniversario de la fundación de la Escuela Superior de Diplomática (1856-2006). Reglamentos y programas. Edición de F. de los Reyes y J. M. ${ }^{a}$ de Francisco. Facultad de Ciencias de la Documentación de la UCM y Real Academia de la Historia. Madrid: 13-32.

Ayarzagüena, M. 1993: "La arqueología prehistórica y protohistórica española en el siglo XIX". Espacio, Tiempo y Forma. Prehistoria y Arqueología 6: 393-411.

Ayarzagüena, M. y Mora, G. (eds.) 2004: Pioneros de la arqueología en España. Del siglo XVI a 1912. Zona Arqueológica 3. Museo Arqueológico Regional. Madrid.

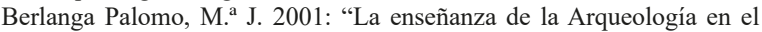
siglo XIX: de las cátedras de Castellanos a la introducción en los estudios universitarios". Anales de Arqueología Cordobesa 12: 13-33.
Bosch Gimpera, P. 1913: "Zur Frage des iberischen Keramik". Memnon. Zeitschrift für die Kunst-und Kulturgeschichte des alten Oriens, VII (3).

Bosch Gimpera, P. 1915: El problema de la cerámica ibérica. Memorias de la Comisión de Investigaciones Paleontológicas y Prehistóricas 7, Museo Nacional de Ciencias Naturales. Madrid.

Bosch Gimpera, P. 1916: L'Edat de la Pedra. Consell de Pedagogia de la Mancomunitat de Catalunya. Barcelona.

Bosch Gimpera, P. 1923a: "La investigació de la cultura ibèrica del Baix Aragó". Anuari de l'Institut d'Estudis Catalans VI (1915-1920): 641-671.

Bosch Gimpera, P. 1923b: “L'estat actual de la investigación de la cultura ibérica". Anuari de l'Institut d'Estudis Catalans VI (1915-1920): 671-694.

Bosch Gimpera, P. 1932. Etnología de la Península Ibèrica. Alpha. Barcelona.

Bosch Gimpera, P. 1975: Prehistoria de Europa. Istmo. Madrid.

Bosch Gimpera, P. y Olivar Bertrand, R. 1978: Correspondència. Proa. Barcelona.

Cabré Aguiló, J. 1908: "Hallazgos arqueológicos". Boletín de Historia y Geografía del Bajo Aragón II: 214-244.

Cabré Aguiló, J. y Calvo, I. 1916, Excavaciones en la cueva y collado de los Jardines (Santa Elena, Jaén). Memorias de la Junta Superior de Excavaciones y Antigüedades 8. Madrid.

Calvo, I. 1914: "Exploraciones arqueológicas en citanias gallegas". Revista de Archivos, Bibliotecas y Museos 31: 63-77.

Calvo, I. 1916: En las ruinas de Clunia. Tipografía de la Revista de Archivos, Bibliotecas y Museos. Madrid.

Canto, A. M. a 2001: "El viaje arquitectónico-anticuario de Fray José Ortíz y Sanz: una carta arqueológica de España a fines del XVIII". Spal 10: 29-55.

Cerralbo, Enrique de Aguilera y Gamboa, marqués de 1909: El alto Jalón, descubrimientos arqueológicos. Imprenta de T. Fortanet. Madrid.

Cerralbo, Enrique de Aguilera y Gamboa, marqués de 1913: "Les fouilles d'Aguilar d'Anguita". Revue des Études Anciens XV (4): $437-$ 439.

Colominas, J. y Durán i Sanpere, A. 1923: "Restes de poblats ibèrics al Pla d'Urgell i Segarra". Anuari de l'Institut d'Estudis Catalans VI (1915-1920): 606-616.

Cortadella, J. 2003: "Historia de un libro que se sostenía por sí mismo: La Etnología de la Península Ibérica de Pere Bosch Gimpera”. En P. Bosch Gimpera: Etnología de la Península Ibèrica. Urgoiti. Pamplona: IX-CCXLIV.

Déchelette, J. 1908-1914: Manuel d'archéologie préhistorique, celtique et gallo-romaine. Alphonse Picard. París.

Díaz-Andreu, M. 1996: “Arqueólogos españoles en Alemania en el primer tercio del siglo XX. Los becarios de la Junta de Ampliación de Estudios: Bosch Gimpera". Madrider Mitteilungen 37: 205-224.

Díaz-Andreu, M. 2004: "Mélida: génesis, pensamiento y obra de un maestro". En J. R. Mélida. Arqueología Española. Urgoiti. Pamplona: I-CXCIX.

Engel, A. y Paris, P. 1906: "Une forteresse ibérique à Osuna (fouilles de 1903)". Nouvelles Archives des Missions scientifiques et littéraires XII: $357-490$.

Fernández Götz, M. A. 2009: “Gustav Kossinna. Análisis crítico de una figura paradigmática de la arqueología europea”. Arqueoweb 11 (1).

Frickenhaus, A. 1908: "Griechische Vasen aus Emporion". Anuari de l'Institut d'Estudis Catalans II: 195-240.

Furgús, J. 1909: “Antigüedades ibéricas del Bajo Aragón”. Boletín de la Sociedad Aragonesa de Ciencias Naturales 8 (2): 31-41.

García Santos, M. 2017: "Los estudios de Prehistoria en las instituciones de enseñanza superior desde la Escuela Superior de Diplomática a la Guerra Civil". En M. Ayarzagüena Sanz, G. Mora y H. Salas Álvarez (eds.): 150 años de Historia de la Arqueología: teoría y método de una disciplina. Sociedad de Historia de la Arqueología, Museo Arqueológico Nacional y Museo Arqueológico Regional de Madrid. Madrid: 705-726.

Gómez-Moreno, M. 1900-1901: Catálogo Monumental de España. Provincia de Salamanca. Ministerio de Instrucción Pública y Bellas Artes. Madrid. 
Gómez-Moreno, M. 1901-1903: Catálogo Monumental de España. Provincia de Ávila. Ministerio de Instrucción Pública y Bellas Artes. Madrid.

Gómez-Moreno, M. 1905: Catálogo Monumental de España. Provincia de Zamora (1903-1905). Ministerio de Instrucción Pública y Bellas Artes. Madrid.

Gómez-Moreno, M. 1908: Catálogo Monumental de España. Provincia de León (1906-1908). Ministerio de Instrucción Pública y Bellas Artes. Madrid.

Gómez Santa Cruz, S. 1914: El Solar Numantino. Refutación de las Conclusiones Históricas y Arqueológicas defendidas por Adolf Schulten, profesor de la Universidad de Erlangen, como resultado de las Excavaciones que practicó en Numancia y sus inmediaciones. Imprenta de la Revista de Archivos Bibliotecas y Museos. Madrid.

Gracia Alonso, F. 2011: Pere Bosch Gimpera. Universidad, politica, exilio. Marcial Pons Historia. Madrid.

Gracia Alonso, F. 2015a: "La diffusion de la recherche préhistorique espagnole en France. Raymond Lantier et les cours à l'École du Louvre, 1939-1943". En Pour une Histoire de l'Archéologie XVIIIe siècle-1945. Hommage de ses collègues et amis à Éve Gran-Aymerich. Scripta Receptoria 5. Ausonius. Burdeos: 301-320.

Gracia Alonso, F. 2015b: Pensar la Universitat. Escrits de Pere Bosch Gimpera. Universitat de Barcelona. Publicacions i Edicions. Barcelona.

Gracia Alonso, F. 2017: Lluís Pericot. Un prehistoriador entre dos épocas. Urgoiti. Pamplona.

Gracia Alonso, F. 2019: La construcción de una identidad nacional. Arqueología, patrimonio y nacionalismo en Cataluña (1850-1939). Edicions de la Universitat de Barcelona. Barcelona.

Gracia Alonso, F. (en prensa): Ciencia y politica. La organización de la Arqueología y la Prehistoria en España (1850-1939). Universitat de Barcelona. Barcelona.

Gracia Alonso, F. y Fullola Pericot, J. M. "2016: "2 de octubre de 1916. El acceso de Pere Bosch Gimpera a la docencia universitaria, o de cómo la oposición a una cátedra de Historia Antigua marcó el futuro de la Prehistoria en la Universidad española". Pyrenae 47 (1): 7-70.

Gran-Aymerich, E. 2007: Les Chercheurs du Passé. 1798-1945. Aux sources de l'archéologie. CNRS Éditions. París.

Grünert, H. 2002: Gustaf Kossinna (1858-1931). Vom Germanisten zum Prähistoriker. Ein Wissenschaftler im Kaiserreich und in der Weimarer Republik. Verlag Marie Leidorf. Rahden/Westfalen.

Guyotjeannin, O. 1993: "Aperçus sur l'École des Chartes au XIXe". En F. M. Gimeno Blay (ed.): Erudición y discurso histórico: las instituciones europeas (siglos XVIII-XIX). Universidad de valencia. Valencia: 285-307.

Lantier, R. 1917: El santuario ibérico de Castellar de Santisteban. Memorias de la Comisión de Investigaciones Paleontológicas y Prehistóricas, 15. Museo Nacional de Ciencias Naturales. Madrid.

Maier, J. 2008: "La enseñanza de la Arqueología y sus maestros en la Escuela Superior de Diplomática". Revista General de Información y Documentación 18: 173-189.

Mederos, A. 2010-2011: "Hugo Obermaier, el duro camino hacia la cátedra de Historia Primitiva del Hombre (1877-1922)". Boletín de la Asociación Española de Amigos de la Arqueología 46: 235-260.

Mederos, A. 2013: "La etapa final de los arqueólogos de la Escuela Superior de Diplomática: José Ramón Mélida, catedrático de Arqueología y director del Museo Arqueológico Nacional (1912-1930)". Boletín del Seminario de Estudios de Arte y Arqueología 79: 175-223.

Mélida, J. R. 1906: Iberia arqueológica ante-romana: discursos leídos ante la Real Academia de la Historia en la recepción pública del Ilmo. Sr. D. José Ramón y Alinari el día 8 de diciembre de 1906. Tipografía de la viuda e hijos de Tello. Madrid.

Mélida, J. R. 1916: Excavaciones en Numancia. Memoria de los trabajos realizados en 1915. Memorias de la Junta Superior de Excavaciones Arqueológicas, 1. Madrid.
Montelius, O. 1899: Der Orient und Europa. Einfluss der Orientalischen Cultura uf Europa bis zur Mitte des Letzten Jahrtausends V. Chr. Kungl. Estocolmo.

Montelius, O. 1906: Kulturgeschichte Schwedens. Verlag von E. A. Seemann. Leipzig.

Paris, P. 1903-1904: Essai sur l'art et l'industrie de l'Espagne primitive. Leroux. París.

Peiró, I. 1996a: La Escuela Superior de Diplomática. Los archiveros en la historiografía española contemporánea. Asociación Española de Archiveros, Bibliotecarios, Museólogos y Documentalistas. Madrid.

Peiró, I. 1996b: "Los historiadores oficiales de la Restauración (18741910)". Boletín de la Real Academia de la Historia 193 (1): 13-72.

Peiró, I. y Pasamar. G. 1989-1990: "El nacimiento en España de la arqueología y la prehistoria (academicismo y profesionalización, 18561936)". Kalathos 9-10: 9-30.

Pelayo López, F. 2015: "El impacto del darwinismo en la sociedad española del siglo XIX”. Hispania Nova 13: 310-329.

Pelayo López, F. y Gozalo Gutiérrez, R. 2012: Juan Vilanova y Piera (1821-1893), la obra de un naturalista y prehistoriador valenciano. Trabajos Varios del Servicio de Investigación Prehistórica 114, Diputación Provincial de Valencia. Valencia.

Pijoan, J. 1908: "La ceràmica ibèrica a l'Aragó". Anuari de l'Institut d'Estudis Catalans II: 241-262

Quintero, P. 1916: Excavaciones en Punta de la vaca. Cádiz. Memoria acerca de las excavaciones practicadas en 1915. Imprenta de la revista de Archivos, Bibliotecas y Museos. Madrid.

Rada y Delgado, J. de D. de la 1875: Antigüedades del Cerro de los Sanos en términode Montealegre. Imprenta de T. Fortanet. Madrid.

Reinach, S. 1905: "Essai sur l'art el l'industrie de l'Espagne primitive par Pierre Paris”. Revue Archéologique 5: 156-160.

Riera Tuèbols, S. 1994: "El positivisme cientific i la difusió del darwinisme". En AA. VV.: Les ciències naturals $i$ mèdiques a la Renaixença. Història de la cultura catalana, V. Naturalisme, positivisme, catalanisme. Edicions 62. Barcelona: 115-138.

Rubio de la Serna, J. 1888: La necrópolis ante-romana de Cabrera de Mataró. Memorias de la Academia de la Historia. Madrid.

Sánchez Gómez, M. L. 2001: "Etnología y prehistoria en la Universidad Complutense de Madrid. Crónica de una desigual vinculación (19222000)". Complutum 12: 249-272.

Sandars, H. 1913: "The weapons of the Iberians". Archaeologia 64: 205-294.

Sandars, H. 1914: Apuntes. Joyas ibero-romanas halladas en Mojón, cerca de Villacarrillo, en la provincia de Jaén. Imp. Morales. Jaén.

Schmidt, H. 1904: "Troja-Mykene-Ungarn. Archeologische Parallelen". Zeitschrift für Ethnologie XXXVI: 606-645.

Schmidt, H. 1911: "Vorläufiger Bericht über die Ausgrabungen, 1909-10 in Cucuteni bei Jassy (Rumänien)". Zeitschrift für Ethnologie XLIII: 582-601.

Schmidt, H. 1915: Estudios acerca de los principios de la Edad de los Metales en España. Memorias de la Comisión de Investigaciones Paleontológicas y Prehistóricas 8, Museo Nacional de Ciencia Naturales. Madrid.

Schulten, A. 1914: Mis excavaciones en Numancia 1905-1912. Casa Editorial Estudio. Barcelona.

Siret, L. 1913: Questions de Chronologie et d'Ethnologie ibèriques. I "De la fin du quaternaire à la fin du Bronze". Paul Geuthner. Paris.

Vidiella, S. 1908: "Estaciones prehistóricas". Boletín de Historia y Geografía del Bajo Aragón II: 201-213.

Vives Escudero, A. 1917: Estudio de arqueología cartaginesa. La necrópolis de Ibiza. Junta para la Ampliación de Estudios e Investigaciones Científicas. Madrid.

Zuazo Palacios, J. 1915: La villa de Montealegre y su cerro de los Santos. Imprenta de los Hijos de Gómez Fuentenebro. Madrid. 